Research Article

\title{
Study on the Damping Effect of Particle Dampers considering Different Surface Properties
}

\author{
Xiaowei Li $(\mathbb{D}$, Yue Yang, and Weixing Shi $(\mathbb{D}$ \\ Department of Disaster Mitigation for Structures, Tongji University, Shanghai 200092, China \\ Correspondence should be addressed to Weixing Shi; swxtgk@126.com
}

Received 23 April 2019; Revised 27 May 2019; Accepted 18 June 2019; Published 21 July 2019

Academic Editor: Nicola Caterino

Copyright (c) 2019 Xiaowei Li et al. This is an open access article distributed under the Creative Commons Attribution License, which permits unrestricted use, distribution, and reproduction in any medium, provided the original work is properly cited.

\begin{abstract}
Particle dampers are nonlinear vibration control devices. The surface property has a great influence on the performance of the particle damper, but it is difficult to be considered and analyzed. This paper firstly gives a view of how to establish a theoretic model of the particle damper. The dynamic equation and energy dissipation coefficient of collision are revised from the Hertz contact theory in the proposed theoretic model, considering the friction of particles. Then, a contrastive collision model relying on the finite element method is established to verify the reasonability of the theoretic model. The effects of different factors which will have an influence on the performance of the particle damper are discussed, and several conclusions on how to optimize the particle damper are proposed. Except for the aforementioned dynamic analysis, this paper also presents a particle damping index to evaluate the capability of energy dissipation of different materials, in order to facilitate the material selection in the practical design. Finally, an experiment is developed to verify the character of the collision and energy dissipation. The feasibility of the proposed method to estimate the surface property of different particles is validated by the free vibration experiment.
\end{abstract}

\section{Introduction}

Civil structures are suffering from earthquakes and windinduced vibrations. To protect a civil structure, one choice is to strengthen them. However, it may cost a lot but little effect is obtained, which is not sustainable. A sensible choice is to use the structural control technology [1-4], which includes passive control, active control, and semiactive control $[5,6]$. In real projects nowadays, passive control still has the dominant application $[7,8]$. The particle damper is one of the passive controllers [9-11] which can dissipate the vibration energy via friction and impact among the particles filled in a body cavity [12-15]. Particle dampers can be used in a harsh environment because its performance is insensitive to temperature [16-20]. Furthermore, particle dampers can dissipate vibration energy in a relatively broader range of frequency [21-24].

Momentum exchange, friction, and acoustic radiation are generally considered as the main damping mechanism of the particle damper [25-27]. However, there is no consensus yet. Some researchers thought that the particle damper can reduce the response of primary structure via momentum exchange [28-30]. However, others hold the opinion that the momentum exchange cannot dissipate the kinetic energy for transient and random disturbances. Cempel and Lotz [31] investigated the damping performance of particle dampers and found that the energy dissipation was related to the impacts among particles or between particles and the container. Kerwin [32] referred that the particle material consumed the energy of the main structure by three approaches: (a) the friction among the particles, (b) nonlinear deformation of the contacting points among the particles, and (c) the resonance of the particle material. Xu et al. [33] investigated an elastic beam and plate structures with drilled holes filled with particles. They proposed a numerical procedure to predict the damping effect and validated the model predictions by experimental results. Lu et al. [34] adopted an elastoplastic collision model and a simplified frictional-elastic collision model to analyze the energy dissipation due to impact and friction, respectively. They conducted the free vibration tests and aeroelastic wind tunnel tests of a benchmark model attached with particle 
dampers to validate the rationality of the theoretical results. Lu et al. [35] provided an overview of particle damping technology on theoretical analysis and numerical simulation, together with their pros and cons. They tended to hold the opinion that the impact damping is mainly achieved by a certain kind of energy loss that was produced on the basis of the nonperfect elastic collision. Lu et al. [36] supposed that the vibration of the structure was attenuated by nonlinear deformation occurred in collisions among particles and collisions between particles and the container wall. They proposed a simplified numerical simulation method of equating multiple particles to a single particle. The simplified method was used for the preliminary optimal design of a PTMD (particle-tuned mass damper) attached to a five-story steel structure through a shaking table test. Although these researchers have explored that the impact and friction are the main energy dissipation mechanism of particle dampers, they are generally qualitative and based on either experimental experiences or numerical simulations. There is little theoretical research.

The most widely used theory for the particle damping is the discrete element method (DEM) [37, 38]. While the DEM regards the particle as a rigid body, the particles are simplified as elements and the contact between particles is represented by some springs and damper interfaces. DEM does not consider the process of collisions adequately, and it will ignore the influence of materials on the vibration energy dissipation. Consequently, conclusions obtained from DEM must be independent of the properties of the particle surface. In other words, the surface property cannot be considered in the analysis via DEM.

Because the energy absorbed during the plastic deformation is irreversible and is not permanently consumed via momentum exchange, the plastic deformation should be considered as one of the main factors of particle damping. Correspondingly, it is important to study the role of particle surface properties during collision. Therefore, this paper uses the Hertz contact theory as the basis of the collision analysis. The effect of different surface properties on collision is qualitatively evaluated. A new index, named particle damping index, is proposed to identify the particle materials. This index can be applied to the initial design stage of the particle damper to maximize the damping performance from the material's perspective. Finally, an experiment is designed and proposed to verify the theoretical analysis.

\section{Mechanical Model and Theoretical Analysis}

2.1. Hertz Contact Theory. Hertz contact theory, which assumes that periodic positive collisions will occur between two balls under an external excitation, is introduced briefly in this section. In the theory, a motion cycle is divided into three phases [31]: elastic compression, elastoplastic compression, and elastic recovery. Some assumptions are introduced in the collision model, e.g., friction among particles, and friction between particles and the air is ignored during the whole process. The geometric deformation relationship in the elastic phase is still applicable in the elastoplastic phase, and the relationship between the recovery force and relative displacement in the elastic recovery phase is equal to that in the elastic compression phase. The three phases are introduced in the following.

2.1.1. Phase of Elastic Compression. The parameters used in the theoretic model of two collision balls are as follows: elastic moduli $E_{1}$ and $E_{2}$, yield strengths $\sigma_{s 1}$ and $\sigma_{s 2}$, Poisson's ratios $\mu_{1}$ and $\mu_{2}$, radii $R_{1}$ and $R_{2}$, masses $m_{1}$ and $m_{2}$, normal velocities before collision $v_{\mathrm{n} 1}^{-}$and $v_{\mathrm{n} 2}^{-}$, tangential velocities before collision $v_{\mathrm{t} 1}^{-}$and $v_{\mathrm{t} 2}^{-}$, normal velocities after collision $v_{\mathrm{n} 1}^{+}$and $v_{\mathrm{n} 2}^{+}$, tangential velocities after collision $v_{\mathrm{t} 1}^{+}$ and $v_{\mathrm{t} 2}^{+}$, relative deformation during collision $\delta$, contact force $p$, contact radius $r_{\mathrm{a}}$, and plastic zone radius in the contact surface $r_{\mathrm{p}}$. Assuming that $v_{\mathrm{n} 1}^{-}<v_{\mathrm{n} 2}^{-}$, the normal relative velocity before collision will be $v_{\mathrm{rn}}^{-}=v_{\mathrm{n} 1}^{-}-v_{\mathrm{n} 2}^{-}$, while normal relative velocity after collision will be $v_{\mathrm{rn}}^{+}=v_{\mathrm{n} 2}^{+}-v_{\mathrm{n} 1}^{+}$, tangential relative velocity before collision will be $v_{\mathrm{rt}}^{-}=v_{\mathrm{t} 1}^{-}-v_{\mathrm{t} 2}^{-}$, and tangential relative velocity after collision will be $v_{\mathrm{rt}}^{+}=v_{\mathrm{t} 2}^{+}-v_{\mathrm{t} 1}^{+}$.

Contact radius $r_{\mathrm{a}}$ can be written as [38]

$$
r_{\mathrm{a}}=\left[\frac{3 p\left(\left(1 / E_{\mathrm{t} 1}\right)+\left(1 / E_{\mathrm{t} 2}\right)\right)}{4\left(\left(1 / R_{1}\right)+\left(1 / R_{2}\right)\right)}\right]^{1 / 3} .
$$

In equation (1), $E_{\mathrm{t} 1}=E_{1} /\left(1-\mu_{1}^{2}\right)$ and $E_{\mathrm{t} 2}=E_{2} /\left(1-\mu_{2}^{2}\right)$. When $E_{\mathrm{t}}=E_{\mathrm{t} 1} E_{\mathrm{t} 2} /\left(E_{\mathrm{t} 1}+E_{\mathrm{t} 2}\right)$ and $R=R_{1} R_{2} /\left(R_{1}+R_{2}\right), r_{\mathrm{a}}$ can be simplified as

$$
r_{\mathrm{a}}=\left(\frac{3 p R}{4 E_{\mathrm{t}}}\right)^{1 / 3}
$$

The schematic picture of the two-ball collision is shown in Figure 1.

The expression of the relative deformation in the twoball collision is

$$
\delta=\frac{3 p\left(\left(1 / E_{\mathrm{t} 1}\right)+\left(1 / E_{\mathrm{t} 2}\right)\right)}{4 r_{\mathrm{a}}}=\frac{3 p}{4 E_{\mathrm{t}} r_{\mathrm{a}}} .
$$

The following expressions can be obtained from equations (2) and (3):

$$
\begin{aligned}
& r_{\mathrm{a}}^{2}=R \delta, \\
& p=\frac{4}{3} E_{\mathrm{t}} \sqrt{R} \delta^{3 / 2} .
\end{aligned}
$$

Then, the equation of motion in the elastic phase can be written as

$$
m \frac{d^{2} \delta}{d t^{2}}=-\frac{4}{3} E_{\mathrm{t}} \sqrt{R} \delta^{3 / 2}
$$

In equation (6), the equivalent mass $m$ is $m=$ $m_{1} m_{2} /\left(m_{1}+m_{2}\right)$.

According to the Hertz contact theory, the distribution of compressive stress in the elastic contact zone is approximately considered to be spherical. Then, the compressive stress of the point with radius $r$ can be expressed as

$$
\sigma(r)=\frac{\sigma_{\mathrm{c}}}{r_{\mathrm{a}}} \sqrt{r_{\mathrm{a}}^{2}-r^{2}}
$$




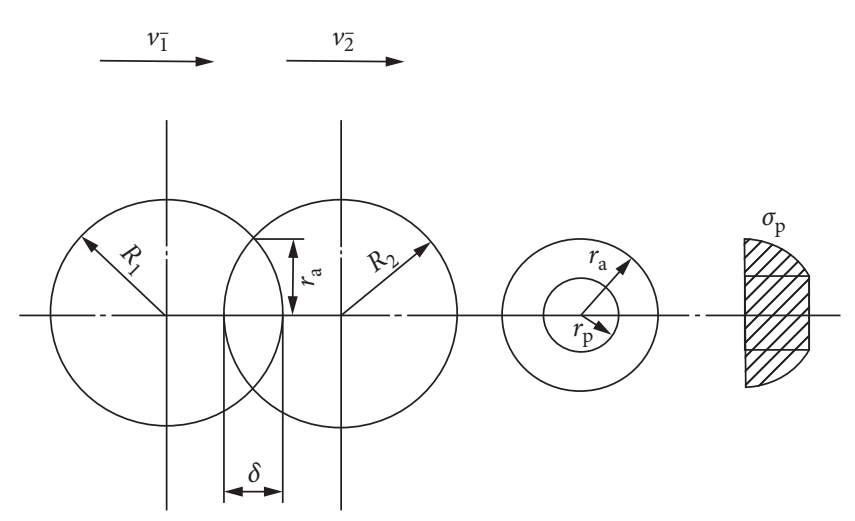

Figure 1: Diagram of two-ball collision.

In equation (7), the contact stress at the contact center $\sigma_{\mathrm{c}}$ can be described as $\sigma_{\mathrm{c}}=3 p / 2 \pi r_{\mathrm{a}}^{2}$.

According to formulas (4) and (5), $\sigma(r)$ is

$$
\sigma(r)=\frac{2 E_{\mathrm{t}}}{\pi R} \sqrt{r_{\mathrm{a}}^{2}-r^{2}}
$$

At the end of the elastic compression phase, the compressive stress at the center of the contact zone reached $\sigma_{\mathrm{p}}=\min \left(\sigma_{\mathrm{p} 1}, \sigma_{\mathrm{p} 2}\right)$, namely, $\sigma_{\mathrm{c}}=\sigma_{\mathrm{p}}$. Because the contact area is relatively small compared to the radius of the sphere, $\sigma_{\mathrm{p} 1}$ and $\sigma_{\mathrm{p} 2}$ can be derived approximately based on the solution of the rigid flat punch pressing:

$$
\begin{aligned}
& \sigma_{\mathrm{p} 1}=\left(1+\frac{\pi}{2}\right) \sigma_{\mathrm{s} 1}, \\
& \sigma_{\mathrm{p} 2}=\left(1+\frac{\pi}{2}\right) \sigma_{\mathrm{s} 2} .
\end{aligned}
$$

Contact radius $r_{\mathrm{a}}$ and relative deformation $\delta_{1}$ can be expressed as

$$
\begin{aligned}
r_{\mathrm{a} 1} & =\frac{\pi \sigma_{\mathrm{p}} R}{2 E_{\mathrm{t}}} \\
\delta_{1} & =R\left(\frac{\pi \sigma_{\mathrm{p}}}{2 E_{\mathrm{t}}}\right)^{2} .
\end{aligned}
$$

Boundary conditions are considered as follows: if $\delta=0$, then $\dot{\delta}=v_{\mathrm{r}}$. Expression of the speed in the elastic compression phase can be obtained by solving equation (6):

$$
v=\sqrt{\left(v_{\mathrm{r}}^{-}\right)^{2}-\frac{16 E_{\mathrm{t}} \sqrt{R}}{15 m} \delta^{5 / 2}}
$$

According to the requirement $\delta=\delta_{1}$, at the end of the elastic compression phase, the expression of relative velocity of two balls are

$$
\dot{\delta}_{1}=\sqrt{\left(v_{\mathrm{r}}^{-}\right)^{2}-\frac{16 E_{\mathrm{t}} \sqrt{R}}{15 m} \delta_{1}^{5 / 2}}
$$

Assuming that the initial condition is $t=0$ and $\delta=0$, the relationship of the relative displacement over time can be obtained by the reintegration of equation (11) via the separation variable method. The expression of the relationship of $t-\delta$ in the elastic compression phase is

$$
t=\int_{0}^{\delta}\left[\left(v_{\mathrm{r}}^{-}\right)^{2}-\frac{16 E_{\mathrm{t}} \sqrt{R}}{15 m} \delta^{5 / 2}\right]^{-1 / 2} d \delta .
$$

At last, the end time of the elastic compression phase can be obtained by the numerical integration:

$$
t_{1}=\int_{0}^{\delta_{1}}\left[\left(v_{\mathrm{r}}^{-}\right)^{2}-\frac{16 E_{\mathrm{t}} \sqrt{R}}{15 m} \delta^{5 / 2}\right]^{-1 / 2} d \delta
$$

2.1.2. Phase of Elastoplastic Compression. As the contact force increases, the plastic zone emerges in the contact center. While the two balls continue to moving mutually, the plastic contact range and elastic contact range gradually expand outward. When $r_{\mathrm{p}}$ represents the radius of the plastic zone at certain moment, then the contact force in the plastic contact zone can be expressed as $r_{\mathrm{p}}=\pi r_{\mathrm{p}}^{2} \sigma_{\mathrm{p}}$. If the stress distribution in the elastic contact zone is still expressed by equation (8), then the total contact force in the elastic annular contact zone can be expressed as

$$
p_{1}=\int_{r_{\mathrm{p}}}^{r_{\mathrm{a}}} \frac{4 r E_{\mathrm{t}}}{R} \sqrt{r_{\mathrm{a}}^{2}-r^{2}} d r=\frac{4 E_{\mathrm{t}}\left(r_{\mathrm{a}}^{2}-r^{2}\right)^{3 / 2}}{3 R}=\frac{\sigma_{\mathrm{p}}^{3} \pi^{3} R^{2}}{6 E_{\mathrm{t}}^{2}} \text {. }
$$

Combining equations (4) and (8), the total contact force in the elastoplastic compression phase will be

$$
p=\frac{\sigma_{\mathrm{p}}^{3} \pi^{3} R^{2}}{6 E_{\mathrm{t}}^{2}}+\pi r_{\mathrm{p}}^{2} \sigma_{\mathrm{p}}=\pi R \sigma_{\mathrm{p}} \delta-\frac{\sigma_{\mathrm{p}}^{3} \pi^{3} R^{2}}{12 E_{\mathrm{t}}^{2}} .
$$

Similarly, the motion equation in the elastoplastic compression phase using Newton's law can be written as

$$
m \frac{d^{2} \delta}{d t^{2}}=-\left(\pi R \sigma_{\mathrm{p}} \delta-\frac{\sigma_{\mathrm{p}}^{3} \pi^{3} R^{2}}{12 E_{\mathrm{t}}^{2}}\right) .
$$

Considering the boundary condition as follows: if $\delta=\delta_{1}$, then $\dot{\delta}=\dot{\delta}_{1}$. The velocity expression in the elastoplastic compression phase is

$$
v=\sqrt{\dot{\delta}_{1}^{2}+\frac{\sigma_{\mathrm{p}}^{5} \pi^{5} R^{3}}{48 m E_{\mathrm{t}}^{2}}+\frac{\sigma_{\mathrm{p}}^{3} \pi^{3} R^{2}}{6 m E_{\mathrm{t}}^{2}} \delta-\frac{\pi R \sigma_{\mathrm{p}}}{m} \delta^{2}}
$$

The relative speed of the ball reduces to 0 , which means that $\dot{\delta}=0$; when the elastoplastic phase ends, the relative deformation $\delta_{2}$ is

$$
\delta_{2}=\delta_{\max }=\sqrt{\left(\frac{\sigma_{\mathrm{p}}^{2} \pi^{2} R}{6 E_{\mathrm{t}}^{2}}\right)^{2}+\frac{m \dot{\delta}_{1}^{2}}{\pi R \sigma_{\mathrm{p}}}}+\frac{\sigma_{\mathrm{p}}^{2} \pi^{2} R}{12 E_{\mathrm{t}}^{2}} .
$$

Initial conditions are $t=t_{1}$ and $\delta=\delta_{1}$. The relationship of the relative displacement over time can be obtained by the reintegration of equation (18) via the separation variable method. The expression of the relationship of $t-\delta$ in the elastoplastic compression phase is 


$$
t=t_{1}+\int_{\delta_{1}}^{\delta}\left(\dot{\delta}_{1}^{2}+\frac{\sigma_{\mathrm{p}}^{5} \pi^{5} R^{3}}{48 m E_{\mathrm{t}}^{4}}+\frac{\sigma_{\mathrm{p}}^{3} \pi^{3} R^{2}}{6 m E_{\mathrm{t}}^{2}} \delta-\frac{\pi R \sigma_{\mathrm{p}}}{m} \delta^{2}\right)^{-1 / 2} d \delta
$$

At last, the end time of the elastoplastic compression phase can be obtained by the numerical integration:

$$
t_{2}=t_{1}+\int_{\delta_{1}}^{\delta_{2}}\left(\dot{\delta}_{1}^{2}+\frac{\sigma_{\mathrm{p}}^{5} \pi^{5} R^{3}}{48 m E_{\mathrm{t}}^{4}}+\frac{\sigma_{\mathrm{p}}^{3} \pi^{3} R^{2}}{6 m E_{\mathrm{t}}^{2}} \delta-\frac{\pi R \sigma_{\mathrm{p}}}{m} \delta^{2}\right)^{-1 / 2} d \delta
$$

2.1.3. Phase of Elastic Recovery. Two balls will move away from each other after the collision; in other words, the relative speed drops to 0 . The contact force in this phase is considered to be elastic recovery. Moreover, the relationship between the elastic recovery force and relative deformation in this phase is assumed to be equal to that in the elastic compression phase, except the deformation in the elastic recovery phase, which contains an irreversible plastic deformation $\delta_{\mathrm{p}}$. The contact force in the elastic recovery phase can be expressed as

$$
p=\frac{4}{3} E_{\mathrm{t}} \sqrt{R}\left(\delta-\delta_{\mathrm{p}}\right)^{3 / 2}
$$

The force between the two balls is identical at the end of the second phase (elastoplastic compression) and the beginning of the third phase (elastic recovery). An expression can be obtained as follows:

$$
\pi R \sigma_{\mathrm{p}} \delta_{2}-\frac{\sigma_{\mathrm{p}}^{3} \pi^{3} R^{2}}{12 E_{\mathrm{t}}^{2}}=\frac{4}{3} E_{\mathrm{t}} \sqrt{R}\left(\delta-\delta_{\mathrm{p}}\right)^{3 / 2}
$$

And then, $\delta_{\mathrm{p}}$ can be written as

$$
\delta_{\mathrm{p}}=\delta_{2}-\left[\frac{3}{4 E_{\mathrm{t}} \sqrt{R}}\left(\pi R \sigma_{\mathrm{p}} \delta_{2}-\frac{\sigma_{\mathrm{p}}^{3} \pi^{3} R^{2}}{12 E_{\mathrm{t}}^{2}}\right)\right]^{2 / 3} .
$$

The motion equation in the elastic recovery phase is

$$
m \frac{d^{2} \delta}{d t^{2}}=-\frac{4}{3} E_{\mathrm{t}} \sqrt{R}\left(\delta-\delta_{\mathrm{p}}\right)^{3 / 2}
$$

Considering the boundary conditions as follows: if $\delta=\delta_{2}$, then $\dot{\delta}=0$. The velocity expression in the elastic recovery phase is

$$
v=-\sqrt{\frac{16}{15} \frac{E_{\mathrm{t}} \sqrt{R}}{m}\left(\delta_{2}-\delta_{\mathrm{p}}\right)^{5 / 2}-\frac{16}{15} \frac{E_{\mathrm{t}} \sqrt{R}}{m}\left(\delta-\delta_{\mathrm{p}}\right)^{5 / 2} .}
$$

A negative value is taken in equation (26) because the direction of relative deformation in the elastic recovery phase is opposite to the relative velocity. Considering that $\delta=\delta_{\mathrm{p}}$ at the end of elastic recovery phase, the relative speed at the end of the whole collision of the two balls is

$$
v_{\mathrm{r}}^{+}=v_{2}^{+}-v_{1}^{+}=\sqrt{\frac{16}{15} \frac{E_{\mathrm{t}} \sqrt{R}}{m}\left(\delta_{2}-\delta_{\mathrm{p}}\right)^{5 / 2}} .
$$

Initial conditions are $t=t_{2}$ and $\delta=\delta_{2}$. The relationship of the relative displacement over time can be obtained by the reintegration of equation (26) via the separation variable method. The expression of the relationship of $t-\delta$ in elastic recovery phase is

$$
t=t_{2}-\int_{\delta_{2}}^{\delta}\left(\frac{16}{15} \frac{E_{\mathrm{t}} \sqrt{R}}{m}\left(\delta_{2}-\delta_{\mathrm{p}}\right)^{5 / 2}-\frac{16}{15} \frac{E_{\mathrm{t}} \sqrt{R}}{m}\left(\delta-\delta_{\mathrm{p}}\right)^{5 / 2}\right)^{-1 / 2} d \delta .
$$

At last, the end time of the elastic recovery phase can be obtained by the numerical integration:

$$
t_{3}=t_{2}-\int_{\delta_{2}}^{\delta_{\mathrm{p}}}\left(\frac{16}{15} \frac{E_{\mathrm{t}} \sqrt{R}}{m}\left(\delta_{2}-\delta_{\mathrm{p}}\right)^{5 / 2}-\frac{16}{15} \frac{E_{\mathrm{t}} \sqrt{R}}{m}\left(\delta-\delta_{\mathrm{p}}\right)^{5 / 2}\right)^{-1 / 2} d \delta .
$$

2.1.4. Definition of the Energy Dissipation Factor. Figure 2 shows the curve of collision duration and relative deformation of three phases. The detailed derivation can be found in Sections 2.1.1 2.1.3.

A cycle of collision is composed of three phases, i.e., the beginning of contact, relative motion, and finally separation. Then, the recovery factor is defined as

$$
e=\frac{v_{2}^{+}-v_{1}^{+}}{v_{1}^{-}-v_{2}^{-}}=\frac{v_{\mathrm{r}}^{+}}{v_{\mathrm{r}}^{-}}
$$

The energy loss value is obtained by calculating the difference in kinetic energy before and after collision. Firstly, the conservation of momentum during collision is displayed:

$$
m_{1} v_{1}^{-}+m_{2} v_{2}^{-}=m_{1} v_{1}^{+}+m_{2} v_{2}^{+}
$$

The speed expression of two balls after the collision can be obtained through equation (27):

$$
\begin{aligned}
& v_{1}^{+}=v_{1}^{-}-\frac{(1+e) m_{2}\left(v_{1}^{-}-v_{2}^{-}\right)}{m_{1}+m_{2}}, \\
& v_{2}^{+}=v_{2}^{-}-\frac{(1+e) m_{1}\left(v_{1}^{-}-v_{2}^{-}\right)}{m_{1}+m_{2}} .
\end{aligned}
$$

The energy dissipation factor $\eta$ is defined as the ratio of the kinetic energy loss after the collision to the kinetic energy before:

$$
\eta=\frac{\left[(1 / 2) m_{1}\left(v_{1}^{-}\right)^{2}+(1 / 2) m_{2}\left(v_{2}^{-}\right)^{2}\right]-\left[(1 / 2) m_{1}\left(v_{1}^{+}\right)^{2}+(1 / 2) m_{2}\left(v_{2}^{+}\right)^{2}\right]}{2 \pi\left[(1 / 2) m_{1}\left(v_{1}^{-}\right)^{2}+(1 / 2) m_{2}\left(v_{2}^{-}\right)^{2}\right]} .
$$

The energy dissipation factor can measure the energy consumption caused by the collision and compare the collision energy consumption effects of different particles.

2.2. Revised Three-Phase Collision. It is unsuitable to analyze the collision of the particles using the Hertz contact theory because it ignores the friction generated during the collision although the specific contribution of friction to energy 


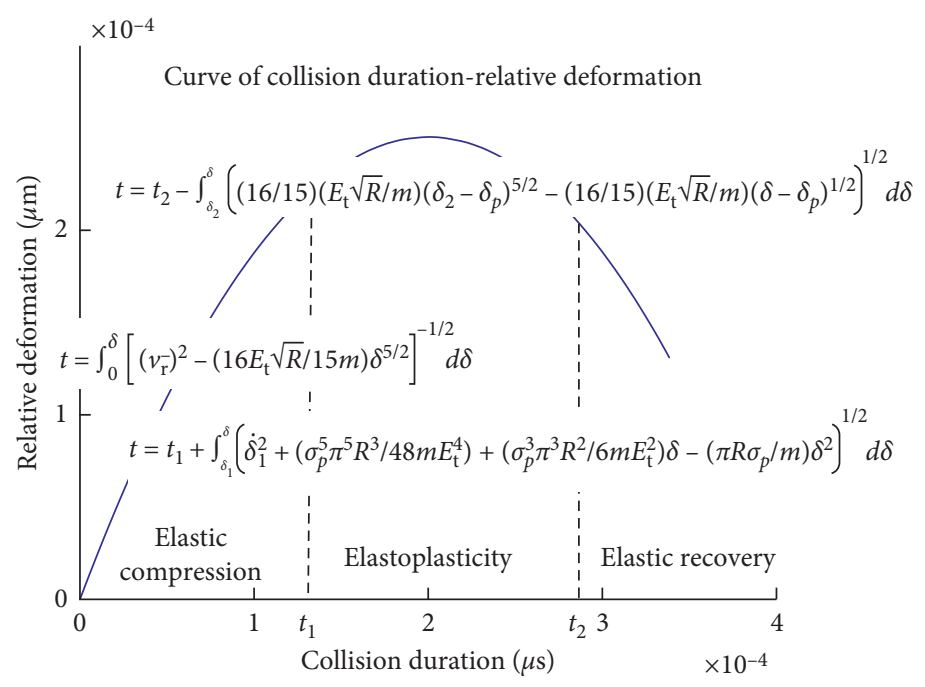

FIGURE 2: Curve of collision duration-relative deformation of three phases.

dissipation is not clear. Especially for the particles with surface properties close to linear elastomers, the main energy dissipation mechanism is the friction consumption, while the inelastic motion hardly occurs. In this paper, the friction mechanism is introduced into the Hertz contact model to revise the collision theory of particles. The friction between the balls is taken into consideration. The superposition of particles in contact is shown in Figure 3.

For a particle, the tangential force is

$$
F_{\mathrm{t}}=-k_{\mathrm{t}} \delta_{\mathrm{t}}-\eta_{\mathrm{t}} G_{\mathrm{ct}} .
$$

Here, $\delta_{\mathrm{t}}$ is a deformation in tangential direction caused by the tangential force; $k_{\mathrm{t}}$ and $\eta_{\mathrm{t}}$ are the stiffness coefficient and damping coefficient in the tangential direction; and $G_{\mathrm{ct}}$ is the relative speed of the contact point in the tangential direction, namely, slip speed. Taking the ball $i$ as an example, $G_{\mathrm{ct}}$ is

$$
G_{\mathrm{ct}}=v_{\mathrm{ti}}-v_{\mathrm{t} j}+r_{i}\left(\omega_{\mathrm{ti}}-\omega_{\mathrm{t} j}\right) .
$$

In the equation (35), $r_{i}$ is the radius of the ball, $\omega_{\mathrm{ti}}$ and $\omega_{\mathrm{t} j}$ is the tangential acceleration of ball $i$ and ball $j$. Stiffness coefficient $k_{\mathrm{t}}$ in equation (34) can be determined according to the Hertz contact theory. The damping coefficient can be obtained through the following formula:

$$
\eta_{\mathrm{t}}=\alpha \sqrt{\mathrm{mk}_{n}}
$$

Coefficient $\alpha$ is related to the recovery factor and usually set as $2[35]$.

If the following condition is detected during the collision, i.e., when the tangential frictional force is greater than the static frictional force, mutual movement between the two balls occurs:

$$
\left|F_{\mathrm{t}}\right|>u_{\mathrm{s} j}\left|F_{n}\right| \text {. }
$$

$\mu_{\mathrm{s} j}$ is the coefficient of static friction between the balls. The tangential force at this moment is revised as

$$
F_{\mathrm{t}}=-u_{\mathrm{sd}} F_{n} .
$$

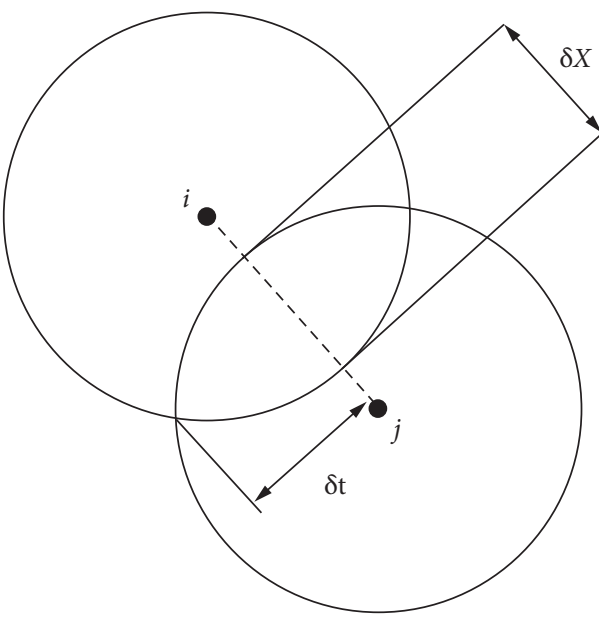

FIgURE 3: Superposition of particles in contact.

$\mu_{\mathrm{sd}}$ is the coefficient of dynamic friction between the balls. The existence of tangential velocity makes it possible for tangential mutual movement between the balls. The existence of tangential force and deformation makes it possible for the dissipation of energy. Therefore, the energy consumed by friction is

$$
\Delta E_{\mathrm{f}}=u_{\mathrm{sd}}\left|F_{n} \delta_{\mathrm{t}}\right| .
$$

The relative tangential velocity of two balls is $v_{\mathrm{r}}^{\mathrm{t}}=v_{1}^{\mathrm{t}}-v_{2}^{\mathrm{t}}$. At the moment the collision begins, take $\delta_{\mathrm{t}}=0$ and ignore the rolling of the ball, which means setting the $\omega_{\mathrm{t} 1}$ and $\omega_{\mathrm{t} 2}$ to be 0 . Take $k_{\mathrm{t}}=640 \mathrm{~N}_{0}^{0.65} / 1+0.05 \mathrm{~N}_{0}^{0.65}$, in which $\mathrm{N}_{0}$ is the normal positive pressure. Assuming that the normal action is a linear collision, $p=4 / 3 E_{\mathrm{t}} \sqrt{R} \delta$. The tangential force is

$$
\begin{aligned}
F_{\mathrm{t}}=-k_{\mathrm{t}} \delta_{\mathrm{t}}-\eta_{\mathrm{t}} G_{\mathrm{ct}} & =\alpha \sqrt{\mathrm{mk}_{n}}\left(v_{\mathrm{t} 1}-v_{\mathrm{t} 2}\right) \\
& =2 \times \sqrt{m \times \frac{4}{3} E_{\mathrm{t}} \sqrt{R}}\left(v_{\mathrm{t} 1}-v_{\mathrm{t} 2}\right) .
\end{aligned}
$$


If $\left|F_{\mathrm{t}}\right|>\mu_{\mathrm{s} j} \cdot p$, that is, the mutual movement in the tangential direction occurs, $F_{\mathrm{t}}$ can be expressed as

$$
F_{\mathrm{t}}=u_{\mathrm{sd}} \frac{4}{3} E_{\mathrm{t}} \sqrt{R} \delta
$$

Exit form of collision of the balls can be described in two types: the tangential direction collision exit previously or the normal direction collision exist previously. That is, the normal collision can exit in the phase of elastic compression, or elastoplastic compression or elastic recovery, depending on the exit of tangential direction collision. The analysis process is shown in Figure 4.

2.3. Revised Energy Dissipation Factor considering the Tangential Friction. Assumed that the normal motion can fully experience the three-phase collision (elastic compression, elastoplastic compression, and elastic recovery), Zhang [39] proposed a simplified formula which can be used to describe the energy dissipation factor:

$$
\begin{aligned}
E_{\mathrm{k} 0}-E_{\mathrm{k}}= & \frac{1}{2} m\left\{\left[\left(1-e^{2}\right)-(1+e)^{2} \frac{7 \mu_{\mathrm{s}}^{2}}{2}\right]\left(v_{01 \mathrm{n}}-v_{02 \mathrm{n}}\right)^{2}\right. \\
& \left.+2(1+e) \mu_{\mathrm{s}}\left(v_{01 \mathrm{n}}-v_{02 \mathrm{n}}\right)\left(v_{01 \mathrm{t}}-v_{02 \mathrm{t}}\right)\right\} .
\end{aligned}
$$

In the formula, $E_{\mathrm{k} 0}-E_{\mathrm{k}}$ is the difference of kinetic energy before and after the collision; $m$ is the effective mass of the two-ball system, $m=m_{1} \cdot m_{2} / m_{1}+m_{2} ; e$ is the

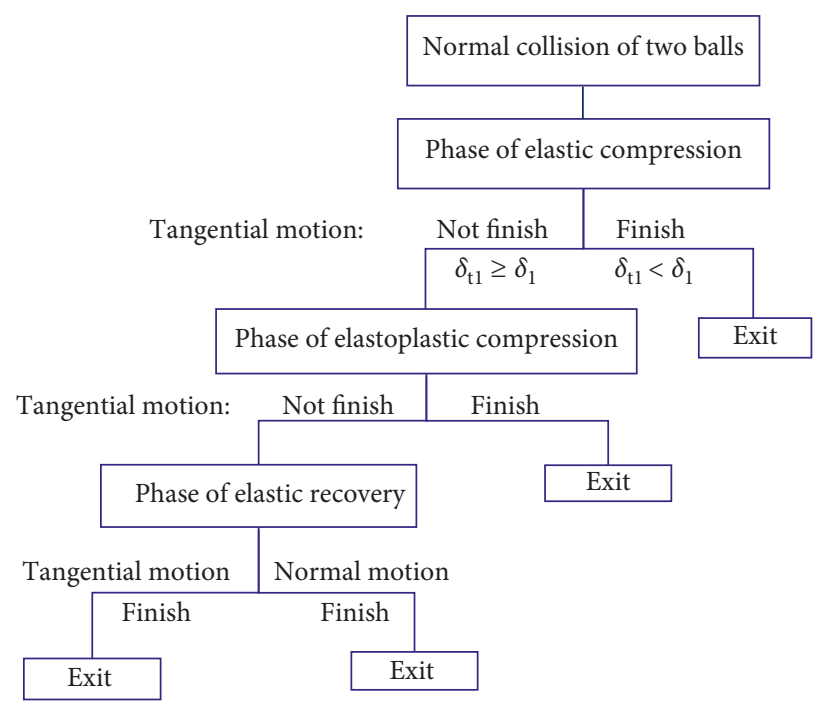

FIgURE 4: Analysis process of the revised Hertz contact theory considering the tangential friction.

recovery factor; $\mu_{\mathrm{s}}$ is the dynamic friction coefficient between the balls; and $v_{01 \mathrm{n}}, v_{02 \mathrm{n}}, v_{01 \mathrm{t}}$, and $v_{02 \mathrm{t}}$ represent the initial normal velocity of two balls and initial tangential velocity of two balls, respectively. This formula can approximately describe the correlation between the normal and tangential collisions.

The revised energy dissipation factor is obtained by referring to equation (42):

$$
\eta=\frac{\left[(1 / 2) m_{1}\left(v_{1}^{-}\right)^{2}+(1 / 2) m_{2}\left(v_{2}^{-}\right)^{2}\right]-\left[(1 / 2) m_{1}\left(v_{\mathrm{n} 1}^{+}\right)^{2}+(1 / 2) m_{2}\left(v_{\mathrm{n} 2}^{+}\right)^{2}\right]+m(1+e) \mu_{\mathrm{s}}\left(v_{\mathrm{n} 1}^{-}-v_{\mathrm{n} 2}^{-}\right)\left(v_{\mathrm{t} 1}^{-}-v_{\mathrm{t} 2}^{-}\right)}{2 \pi\left\{(1 / 2) m_{1}\left[\left(v_{\mathrm{n} 1}^{-}\right)^{2}+\left(v_{\mathrm{t} 1}^{-}\right)^{2}\right]+(1 / 2) m_{2}\left[\left(v_{\mathrm{n} 2}^{-}\right)^{2}+\left(v_{\mathrm{t} 1}^{-}\right)^{2}\right]\right\}}
$$

\section{Verification of Finite Element Analysis}

Because the speed before and after the collision is directly related to the kinetic energy and then affects the energy dissipation, accurate estimation of the speed is the key to particle damping. The finite element collision model of two copper balls, with the same material and diameter, is established in ANSYS. Hexahedral solid element (solid 185) is used to simulate the behavior of balls with large strain during collision. The bilinear isotropic model is applied to consider the nonlinear property of the material, and it is suitable for large plastic strain analysis. Material parameters of the balls are elastic modulus $E=120 \mathrm{GPa}$, yield stress $\sigma_{\mathrm{s}}=100 \mathrm{MPa}$, density $\rho=7.9 \times 10^{3} \mathrm{Kg} / \mathrm{m}^{3}$, and Poisson's ratio $\mu=0.33$. Tangential elastic modulus is calculated according to the formula: $G=E / 2(1+\mu)$. Hex/wedge-sweep method is used in dividing the grid, and the grid size is $2 \mathrm{~mm}$. Face-to-face contact pairs are defined via appointing one ball as a target unit (TARGE 170) and appointing another as the contact unit (CONTA 174). The contact type is chosen as "frictional" to consider the effects of friction, and the coefficient of friction is assigned as $\mu_{\mathrm{s}}=0.2$. ANSYS utilizes the contact stiffness (or penalty stiffness, FKN) to ensure the coordination of the contact interface. Small contact stiffness may lead to excessive intrusion in the contact surface, which means that a target surface penetrates the contact surface seriously. Large contact stiffness may cause the jump of the balls apart from each other, as well as the oscillation of calculation results. The contact stiffness is initially set as $0.1 E$, where $E$ is the elastic modulus. Reducing the contact tolerance (FTOLN in ANSYS) also prevents an excessive intrusion of two contact surfaces. If the tolerance is too small, it will make it difficult to be converged. The FTOLN value is set to be 0.1 . The normal and tangential displacement constraints of the balls are released, as well as their rotational constraints along the vertical axis, respectively. Initial speed of each ball is set to be in the normal and tangential direction. Large displacement transient is chosen as the analysis method, and the time at the end of a loadstep is set to be $1.8 \times 10^{-4} \mathrm{~s}$, and the number of substeps is 100 . The results of two methods (theoretic model and finite element model) are compared with different initial velocity 
and diameter of the balls. Initial velocity in the normal direction of the right ball before collision is $-2.5,-1.5,-1.0$, $0.0,0.5$, and $1.0 \mathrm{~m} / \mathrm{s}$ respectively, while the initial velocity in the normal direction of the left ball is $1 \mathrm{~m} / \mathrm{s}$. The initial velocity in the tangential direction of two balls (left ball and right ball) is 0.0 and $0.0,0.1$ and -0.1 , and 0.5 and $-0.5 \mathrm{~m} / \mathrm{s}$. The diameter of the balls $D$ is $5,10,20$, and $30 \mathrm{~mm}$, respectively. The finite element model in ANSYS is shown in Figure 5.

Curves of the before-collision speed and the after-collision speed of the balls are presented in Figures 6 and 7.

The difference between two models (theoretic model and finite element model) can also be observed by comparing the relative deformation of the collision process. Figures 8-10 are curves of collision duration-relative deformation, with different tangential velocities. The $X$-axis is time, and the $Y$ axis is relative deformation. The relative deformation in the finite element model is calculated from the center to center of two balls.

The conclusion can be obtained that the result of the theoretic model coincides well with the finite element model, which can be seen in Figure 8. Results of the theoretic model will have a larger deviation compared with the finite element if considering the tangential speed of the ball. It can be seen that the tendency deviates from Figures 9 and 10. This is owing to the hypothesis of theoretic model that the collision will carry through the whole three-phase collision (elastic compression, elastoplastic compression, and elastic recovery). Actually, if the tangential speed exceeds the limit, collision process will exit prematurely in the elastic compression phase or elastoplastic compression phase. Therefore, if the collision has a large tangential velocity, the theoretic model proposed in this paper cannot be accurately analyzed.

The trends of the curves of collision duration-relative deformation obtained by two models are identical in spite of the discrepancy caused by the tangential movement. Therefore, the theoretic model has a sufficient accuracy in the factor analysis of damping effect with different surface properties.

\section{Parametric Study on the Particle Damping}

The particle damping has a complex correlation with the density, elastic modulus, yield strength, friction coefficient, etc. In order to study the role of a certain factor, we can use the theoretic model of the particle collision established previously and the control variable method to analyze the impact of different factors on energy dissipation.

The discussion on density is shown in Figure 11.

As can be seen from Figure 11, the energy dissipation increases with the increase of density. This owes to that the higher the density is, the larger mass the particles have. Under the same conditions, the inertial force and the plastic deformation generated by the collision increase if the mass increases. Thereby, the energy dissipation factor increases as well. But the energy dissipation factor does not change linearly with density. When the density reaches a certain

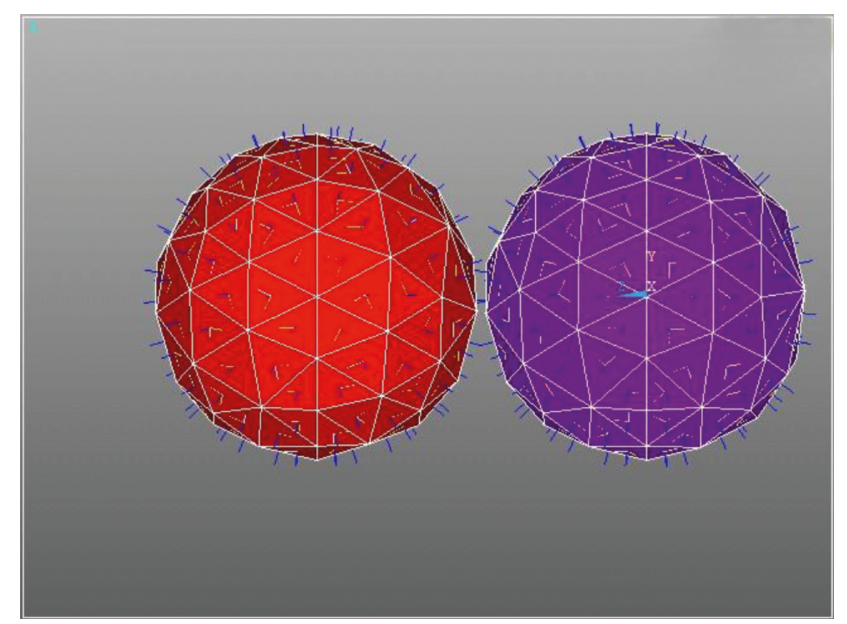

FIGURE 5: Finite element model in ANSYS.

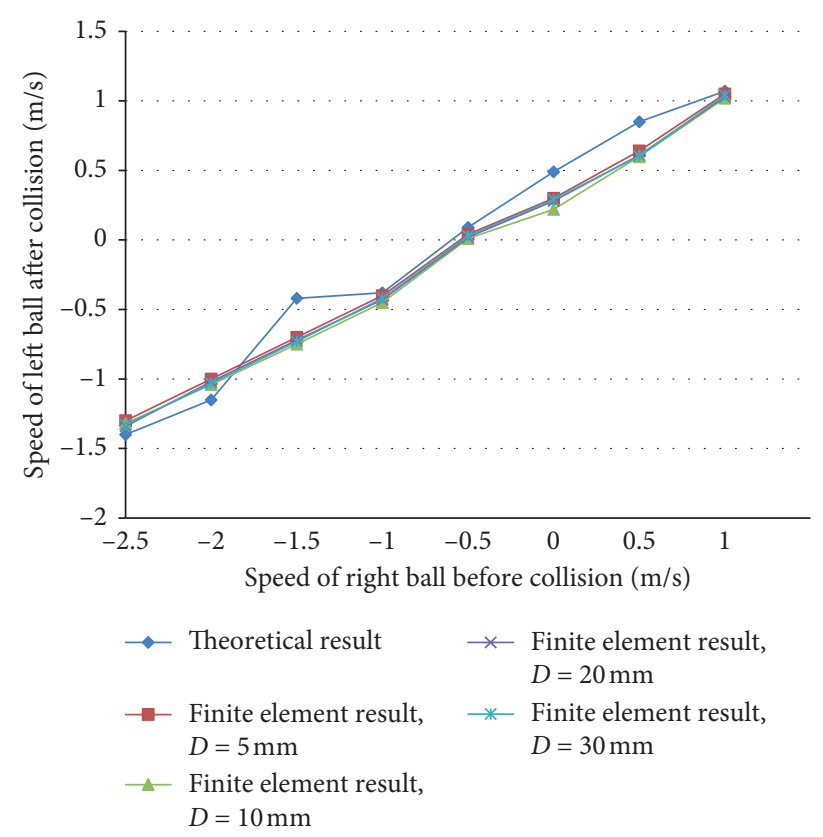

FIGURE 6: Relationship between the after-collision speed of the left ball and the before-collision speed of right ball.

value, the increase of the energy dissipation factor is very small.

The discussion on dynamic friction coefficient is proposed in Figure 12.

As can be seen from Figure 12, the energy dissipation factor increases with the increase of the dynamic friction coefficient. And in the case of tangential velocity increases, the trend of the increase of energy dissipation will be more significant.

The discussion on elastic modulus is presented in Figure 13.

As can be seen from Figure 13, the energy dissipation factor increases with the increase of the elastic modulus. But the rise of the factor is not great except for the curve with a modulus ratio of 0.1. Modulus ratio can be expressed as 


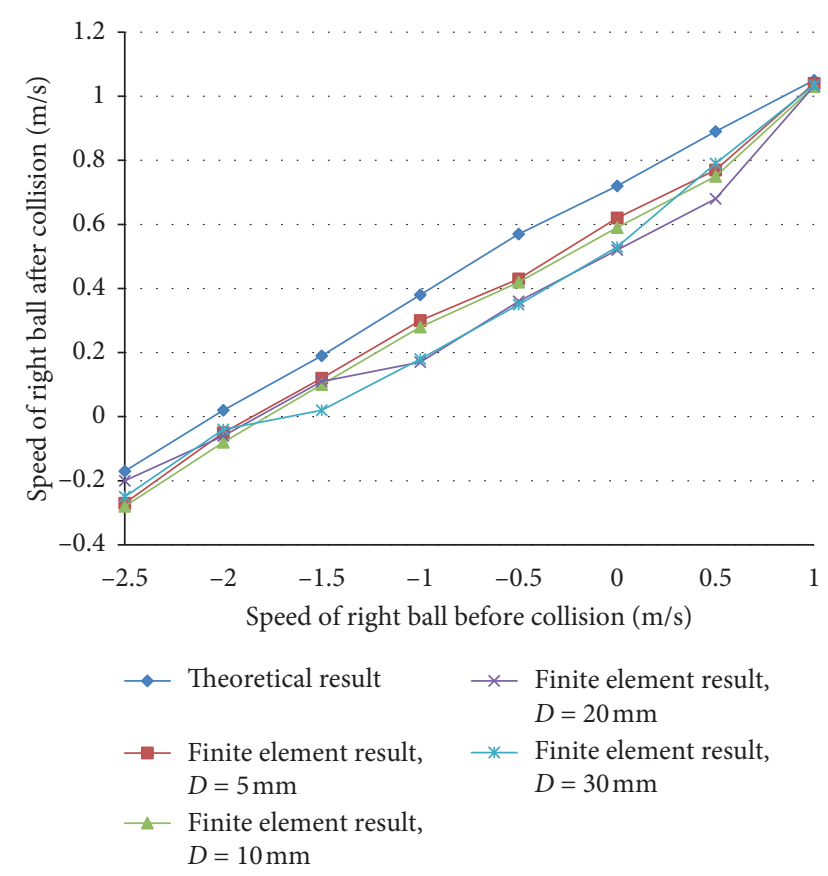

FIGURE 7: Relationship between the after-collision and beforecollision speed of the right ball.

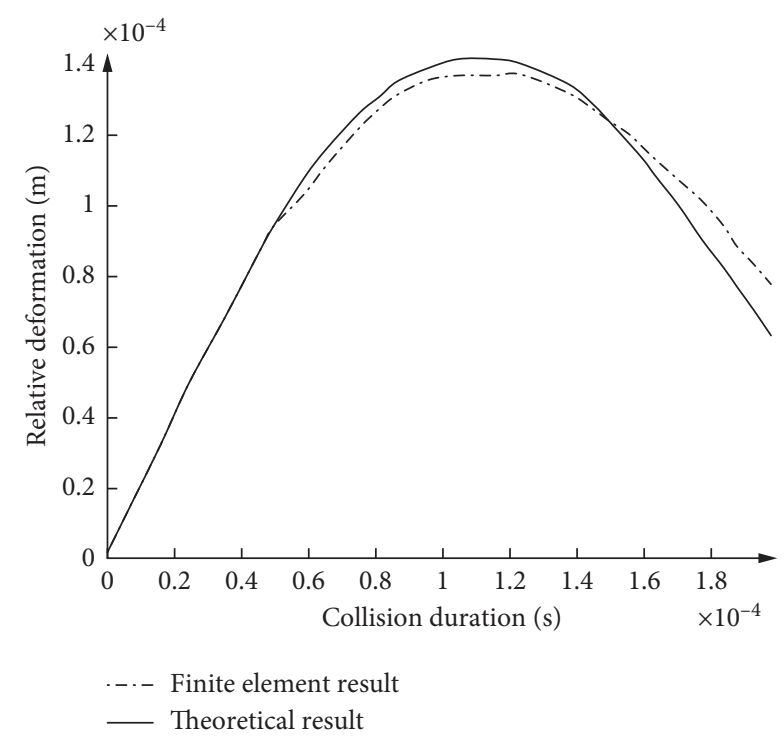

FIGURE 8: Curve of collision duration-relative deformation (tangential velocity of two balls is $0 \mathrm{~m} / \mathrm{s}$ ).

$E_{2} / E_{1} . E_{1}, E_{2}$ is the elastic modulus of the balls. The energy dissipation factor rises when the elastic modulus ratio increases. The rise trend is larger when the elastic modulus ratio is relatively small $(0.1 \sim 10)$, and the trend is smaller when the elastic modulus ratio is relatively large $(10 \sim 100)$. Overall, the increase in the elastic modulus ratio and the increase in the elastic modulus value are not particularly significant for the contribution of the energy dissipation factor.

The discussion on yield strength is shown in Figure 14.

As can be seen from Figure 14, the energy dissipation factor decreases when the yield strength increases. Plastic

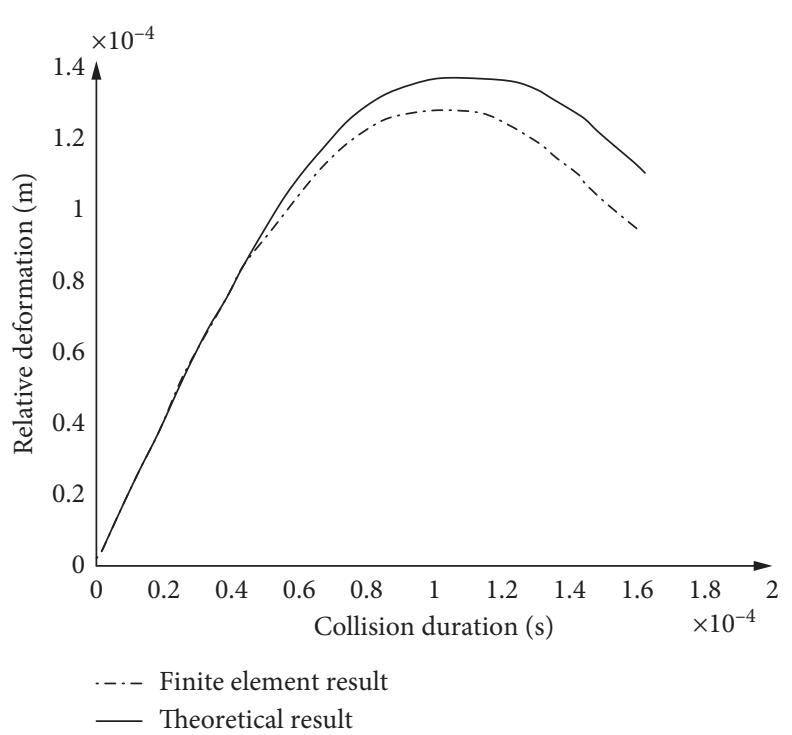

FIGURE 9: Curve of collision duration-relative deformation (tangential velocities of two balls are $0.1 \mathrm{~m} / \mathrm{s}$ and $-0.1 \mathrm{~m} / \mathrm{s}$ ).

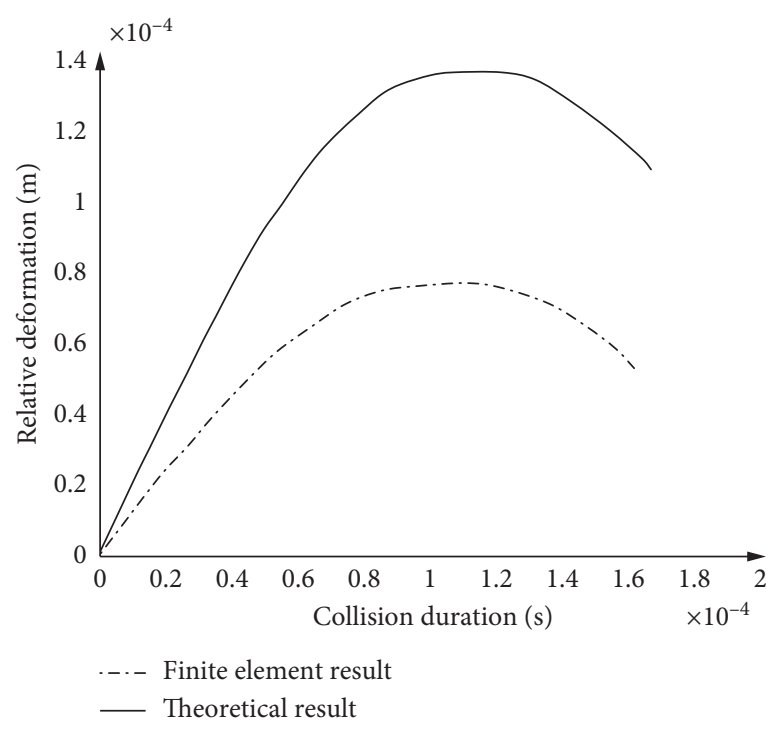

FIgURE 10: Curve of collision duration-relative deformation (tangential velocities of two balls are $0.5 \mathrm{~m} / \mathrm{s}$ and $-0.5 \mathrm{~m} / \mathrm{s}$ ).

deformation has a significant influence on the energy dissipation factor, while the yield strength reflects the ability of plastic deformation of the material. As long as the ball has a small yield strength, which means the material is more susceptible to plastic deformation, the more the vibration energy stored in the plastic deformation, the larger the energy dissipation factor. Yield ratio can be expressed as $\sigma_{\mathrm{s} 2} / \sigma_{\mathrm{s} 1} \cdot \sigma_{\mathrm{s} 1}$ and $\sigma_{\mathrm{s} 2}$ are the yield stress of the balls. When the yield ratio is less than 1, the energy dissipation factor has different decrease trends. When the yield ratio is greater than 1 , all the trends of decrease coincide. This is caused by the hypothesis of the Hertz contact theory: $\sigma_{\mathrm{p}}=\min \left(\sigma_{\mathrm{p} 1}, \sigma_{\mathrm{p} 2}\right)$.

Some factors, e.g., fill ratio, fill position, and excitation, cannot be taken into account because the theoretic model is proposed aiming at the analysis of particle collision process. 


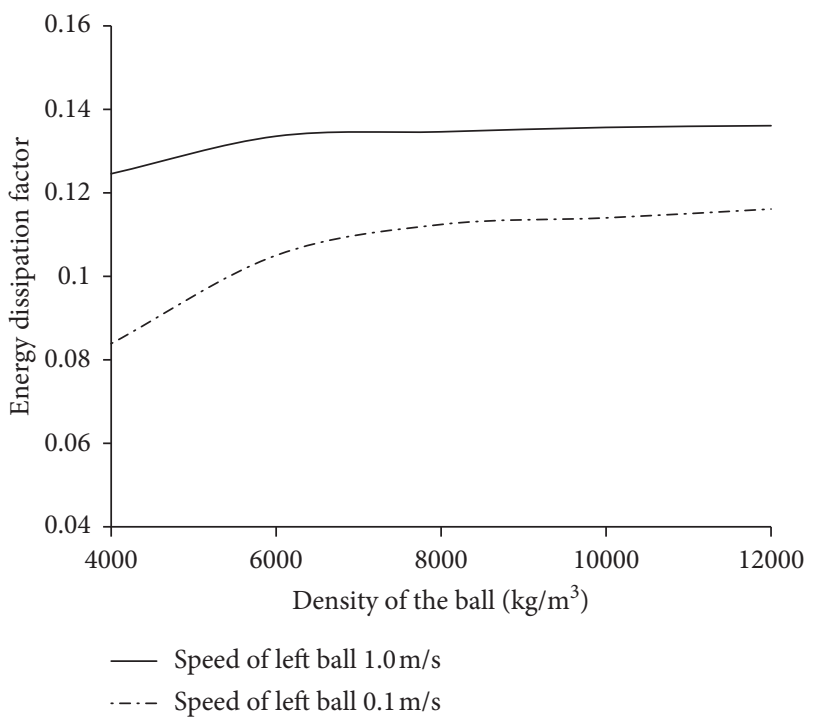

Figure 11: Curve of the energy dissipation factor under different densities.

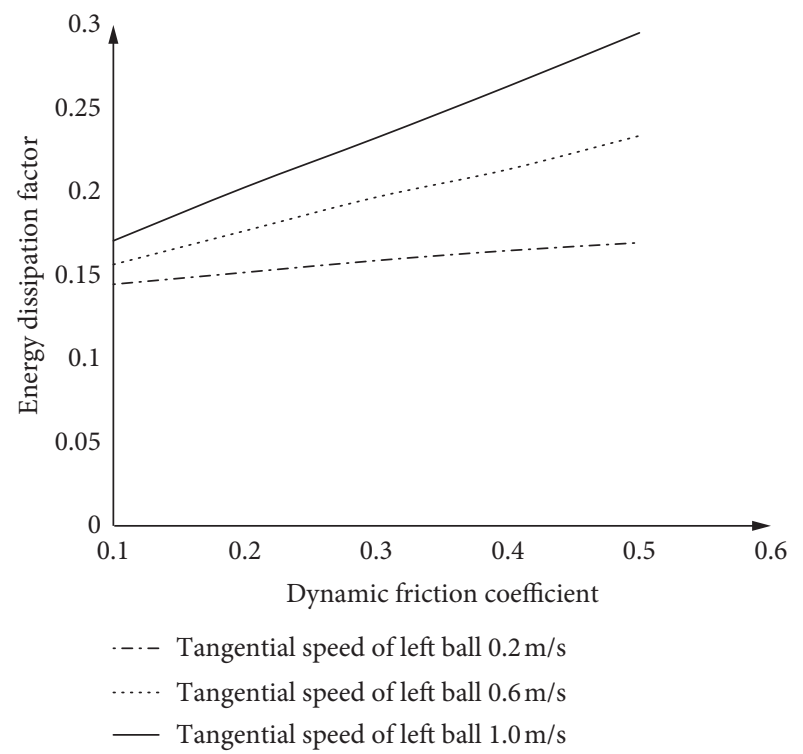

Figure 12: Curve of the energy dissipation factor under different dynamic coefficients of friction.

The discussions focus on the properties of the material. These factors can be studied experimentally. Some conclusions have been drawn by studies as follows. The optimal fill ratio of the particle damper is between $20 \% \sim 40 \%$ [33]. The vibration response of the main structure decreases when the particle mass ratio increases. But the reduction of vibration and increase of mass ratio are not linear [34]. The damping effect of the cylindrical container is better than that of a cuboid, which is probably because the cylindrical container has a good symmetry and the damping effect is not affected by the external excitation direction [34]. The damping effect becomes better with a high relative position to the ground because the high floor will have a larger displacement and more kinetic energy. The vibration of the

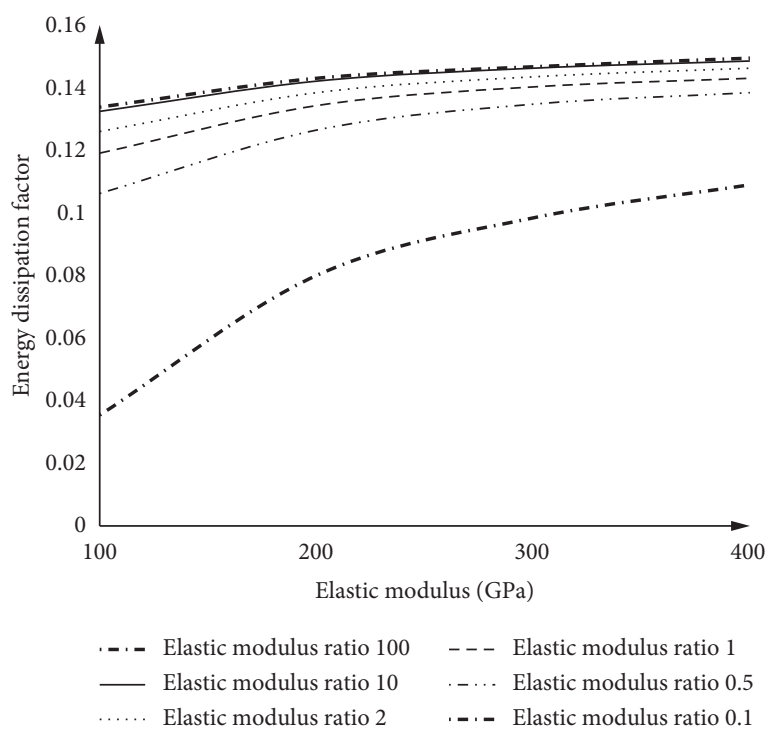

FIgURE 13: Curve of energy dissipation factors under different elastic modulus ratios.

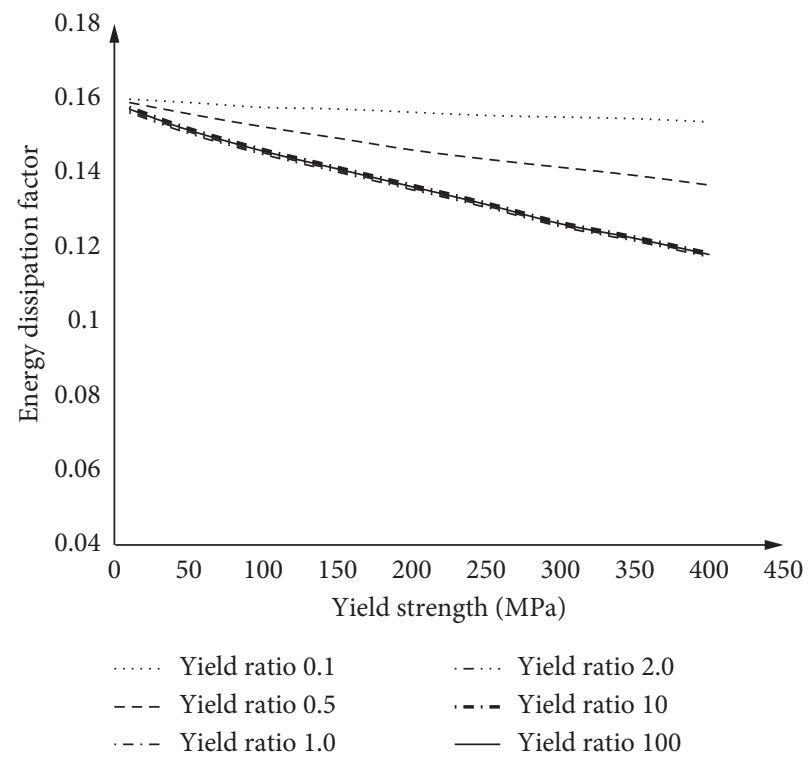

FIGURE 14: Curve of the energy dissipation factor under different yield strengths.

floor will be attenuated via the dissipation of kinetic energy transferred from the structure to the particles [35]. The damping effect of the particle damper will be better if the main structure has a lower inherent damping. The particle damper can reduce the response of the main structure in a wide frequency band, no matter whether the external excitation frequency is close to the natural frequency of the structure. However, the particle damper will have an amplification effect when the external excitation frequency is much smaller than the natural frequency of the main structure [35]. As the intensity of the excitation increases, the particles in the container become more active and the momentum exchange between the particles and main structure also increases, as well as the energy dissipation. But 
TABLE 1: Physical properties and energy consumption of various materials.

\begin{tabular}{lccccccc}
\hline Material & $\begin{array}{c}\text { Elastic modulus, } \\
E(\mathrm{GPa})\end{array}$ & $\begin{array}{c}\text { Yield strength, } \sigma_{\mathrm{s}} \\
(\mathrm{MPa})\end{array}$ & $\begin{array}{c}\text { Density, } \rho e \\
\left(\mathrm{~kg} / \mathrm{m}^{3}\right)\end{array}$ & $\begin{array}{c}\text { Dynamic friction } \\
\text { coefficient, } \mu_{\mathrm{s}}\end{array}$ & $\begin{array}{c}\text { Poisson's } \\
\text { ratio, } \mu\end{array}$ & $\begin{array}{c}\text { Particle damping } \\
\text { index, } \zeta\end{array}$ & $\begin{array}{c}\text { Energy dissipation } \\
\text { factor, } \eta\end{array}$ \\
\hline Copper & 120 & 100 & 8500 & 0.20 & 0.34 & 34.749 & 0.147 \\
Steel & 210 & 210 & 7800 & 0.10 & 0.27 & 14.038 & 0.139 \\
Concrete & 17 & 25 & 2400 & 0.60 & 0.20 & 13.134 & 0.132 \\
Cast iron & 160 & 250 & 7200 & 0.15 & 0.30 & 5.537 & 0.129 \\
Alumina & 70 & 100 & 3100 & 0.50 & 0.25 & 4.748 & 0.131 \\
Glass & 80 & 70 & 2700 & 0.30 & 0.20 & 4.342 & 0.129 \\
Wood (pine) & 14 & 40 & 600 & 0.40 & 0.25 & 1.317 & 0.102 \\
Aluminum alloy & 75 & 300 & 2700 & 0.32 & 0.33 & 0.7448 & 0.087 \\
Rubber & 0.0061 & 7 & 1000 & 0.45 & 0.45 & 0.056 & 0.004 \\
\hline
\end{tabular}

The yield strength of concrete, glass, and alumina in this table uses their compressive strength. The energy dissipation factor is calculated according to the theoretic model established above.

for a certain size of container, the damping effect is no longer affected when the excitation is large enough to provoke all particles to collision [36]. If the particles have different materials, the greater the difference in hardness, that is, the greater the difference in elastic modulus and yield strength is, the more significant the damping effect would be.

\section{Evaluation of Particle Materials}

The collision balls used in particle dampers generally have the same material, meaning the same size, mass, mechanical properties, etc. According to the derivation of the theoretic model above, a dimensionless coefficient named particle damping index $\zeta$ is proposed to indicate the energy-consuming capacity of different particles during the collision:

$$
\zeta=\frac{v E \rho}{\sigma_{\mathrm{s}}^{2}}\left(v_{\mathrm{n}}^{2}+\mu_{\mathrm{s}} v_{\mathrm{t}}^{2}\right)=\frac{3 m v E\left(v_{\mathrm{n}}^{2}+\mu_{\mathrm{s}} v_{\mathrm{t}}^{2}\right)}{4 \pi R^{3} \sigma_{\mathrm{s}}^{2}} .
$$

The particle damping index makes it convenient for the selection and comparison of different materials. Physical properties of several materials which are commonly used are listed in Table 1, as well as the particle damping index and energy dissipation factor. The normal and tangential velocity used in the formulas is set as a fixed value of $1 \mathrm{~m} / \mathrm{s}$ and $0.1 \mathrm{~m} /$ $s$, respectively. As we can see from Table 1, the trend of particle damping index practically coincides with energy dissipation factor. In conclusion, it can be judged that the material has a better performance in energy dissipation if its particle damping index is larger.

\section{Experiment of Particle Dampers}

An experiment is designed to analyze the damping effects of particle dampers filled with different particles. The experimental model is a single-degree-of-freedom (SDOF) frame structure. The bottom of the frame is fixed to the support, and the top is a beam with a relatively large rigidity. After giving an initial displacement in the horizontal direction at the top of the frame, it will swing freely in this direction. The natural frequency of the frame is adjusted to $1 \sim 2 \mathrm{~Hz}$ with reasonable material, size, and top weight, approximately simulating the vibration of tall buildings. The container of the particle damper is glued on the beam. The shape and dimensions of the experimental model are shown in
Figure 15. The measured natural frequency of the frame is $1.69 \mathrm{~Hz}$, and the total weight is $5.76 \mathrm{~kg}$.

The frame is fixed on the experimental site, and the accelerometer is installed on the side wall near to the top. Different kinds (divided into 7 conditions) of particles are fill in the damper container. Types of particles in each case can be seen in Table 2. And a horizontal initial displacement of $30 \mathrm{~mm}$ is placed to the top beam. The frame for free vibration is released and observed, and the vibration attenuation is recorded at the same time. Table 2 also lists the values of the natural frequency and the revised damping ratio of the structure in each case.

Figures 16-22 show the acceleration-time history curves of the frame in 7 cases, as well as the identified frequency via applying Fourier transform and removing interference frequency. The damping ratio of part (b) in Figures 16-22 is a synthesis calculation of multiple vibration periods, and it is related to the initial state of the frame and the length of the intercepted time. The revised damping ratio is calculated again using the logarithmic decay rate method to eliminate the interference of monitoring data, as shown in Table 2.

Conclusions can be obtained from Table 2 and Figures 16-22 as follows:

(1) Vibration of the frame is significantly reduced by the additional particle damper. While the initial damping ratio is $0.45 \%$, the minimum damping ratio of the damper cases is $0.63 \%$ and the maximum damping ratio of the damper cases is $1.41 \%$. The acceleration curves of the frames with dampers attenuate faster, indicating a significant damping effect.

(2) In the cases of the same fill ratio (cases 2, 3, and 4), the damping effect of steel balls is better than the alumina balls and the damping effect of alumina balls is better than the glass balls. In the cases of the same mass ratio (cases 5, 6, and 7), the steel balls still have the best damping effect and the damping effect of 19 glass balls and 7 alumina balls is nearly the same. The regulation of the experiment is identical with that shown in Table 1. The particle damping index $\zeta$ in Table 1 of steel, glass, and alumina is $14.04,4.34$, and 4.75 , respectively. The conclusion obtained from both experimental and theoretical analysis is that the 


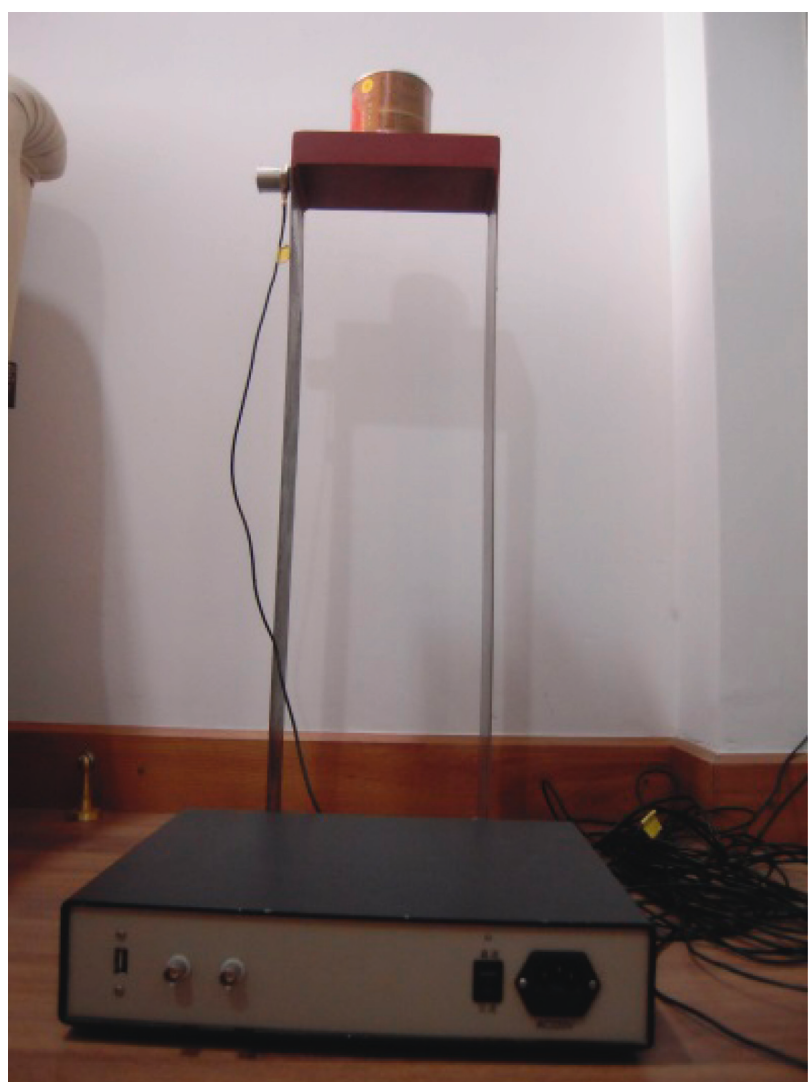

(a)

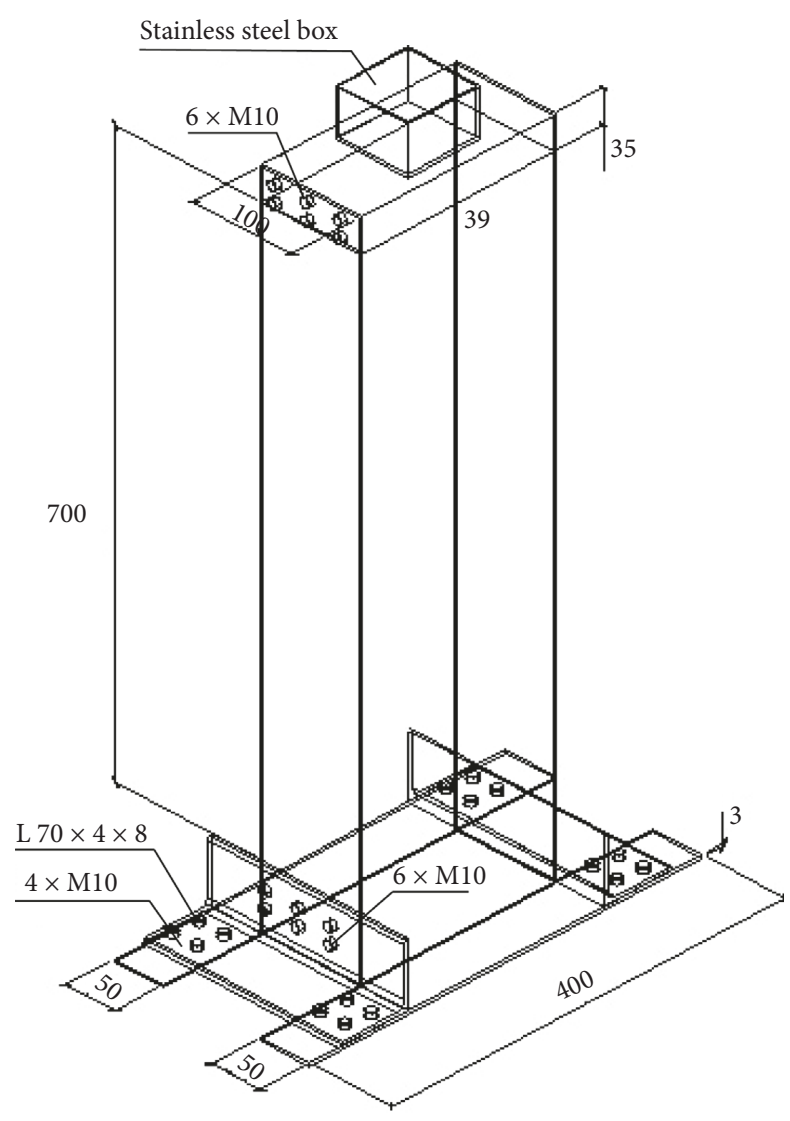

(b)

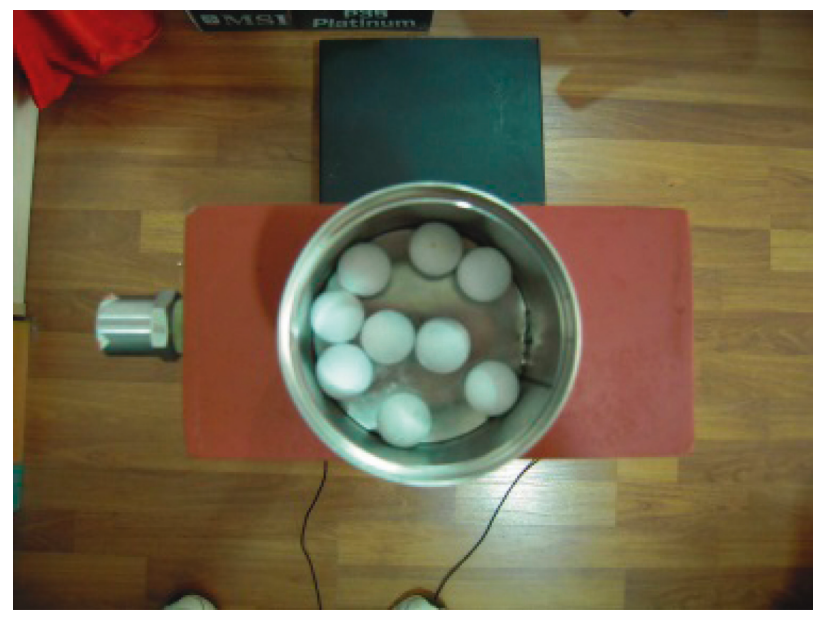

(c)

FIgURE 15: Experimental model of the SDOF frame structure (Unit: mm). (a) Photo. (b) Size. (c) Particle damper.

damping effect of some "flexible" materials (such as copper and lead) is better than that of the "brittle" materials (such as stone and glass).

(3) In the cases of the same fill ratio (cases 2, 3, and 4), the difference of damping effect in material selection is very significant, while the damping ratio changes from $1.41 \%$ to $0.98 \%$ to $0.68 \%$. In the cases of the same mass ratio (cases 5,6 , and 7 ), the difference of damping effect in material selection is not significant, while the damping ratio changes from $0.79 \%$ to
$0.61 \%$ to $0.63 \%$. In summary, when the mass ratio of the particles is adjusted properly, it is possible to choose particles which are inexpensive and easy to access.

(4) In the cases of the same particle material (cases 2 and 5,3 and 6, and 4 and 7), the mass ratio of "flexible" materials will have a more significant impact on damping than that of the "brittle" materials. For example, when the mass ratio's increase is same, the damping effect becomes better for the steel balls than 
TABLE 2: Natural frequency and revised damping ratio of each case.

\begin{tabular}{|c|c|c|c|c|c|c|}
\hline Case & Particles & Natural frequency $(\mathrm{Hz})$ & Revised damping ratio (\%) & Fill ratio $(\%)$ & Mass ratio (\%) & Remarks \\
\hline 1 & Empty & 1.69 & 0.45 & - & 0.00 & Free vibration \\
\hline 2 & 9 steel balls, $D=20 \mathrm{~mm}$ & 1.65 & 1.41 & 70 & 10.99 & \\
\hline 3 & 9 alumina balls, $D=20 \mathrm{~mm}$ & 1.68 & 0.95 & 70 & 4.72 & Same fill ratio \\
\hline 4 & 14 glass balls, $D=15 \mathrm{~mm}$ & 1.67 & 0.69 & 70 & 2.75 & \\
\hline 5 & 3 steel balls, $D=20 \mathrm{~mm}$ & 1.68 & 0.79 & 24 & 3.66 & \\
\hline 6 & 7 alumina balls, $D=20 \mathrm{~mm}$ & 1.67 & 0.61 & 55 & 3.66 & Same mass ratio \\
\hline 7 & 19 glass balls, $D=15 \mathrm{~mm}$ & 1.68 & 0.63 & 95 & 3.66 & \\
\hline
\end{tabular}

Fill ratio: projecting from the top to bottom, the ratio of the balls' area to the bottom area of the container. Mass ratio: ratio of particle mass to frame mass.

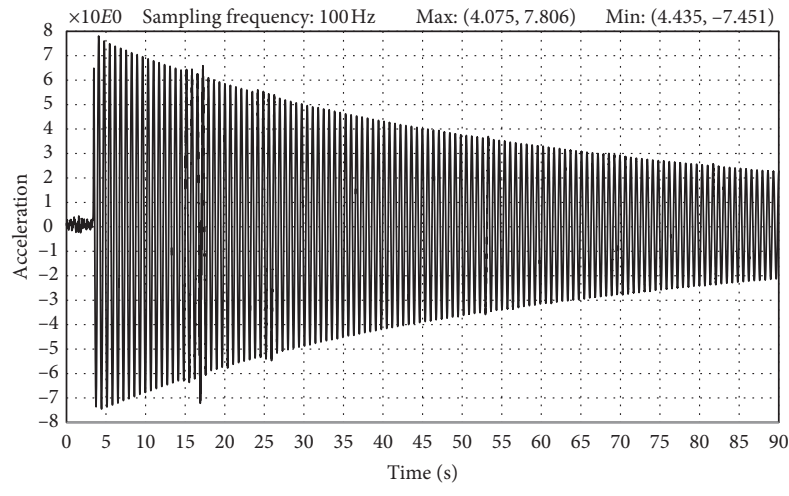

(a)

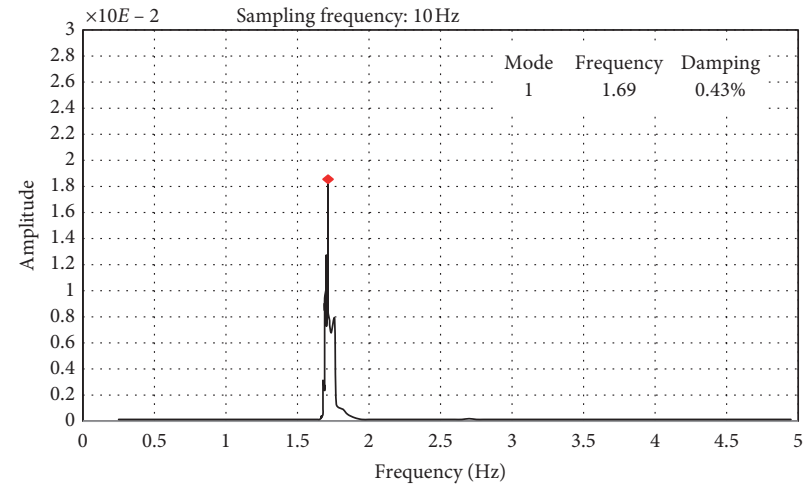

(b)

Figure 16: Monitoring results without the particle damper. (a) Acceleration-time history curve of the frame. (b) Identified frequency and damping ratio.

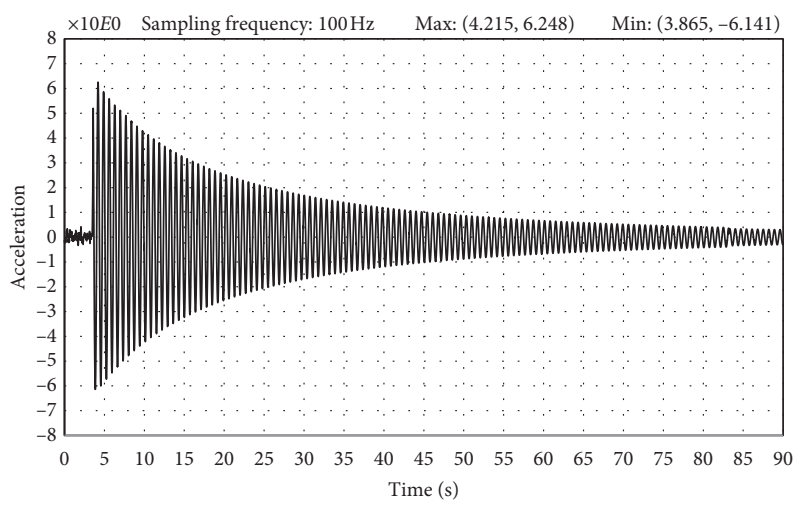

(a)

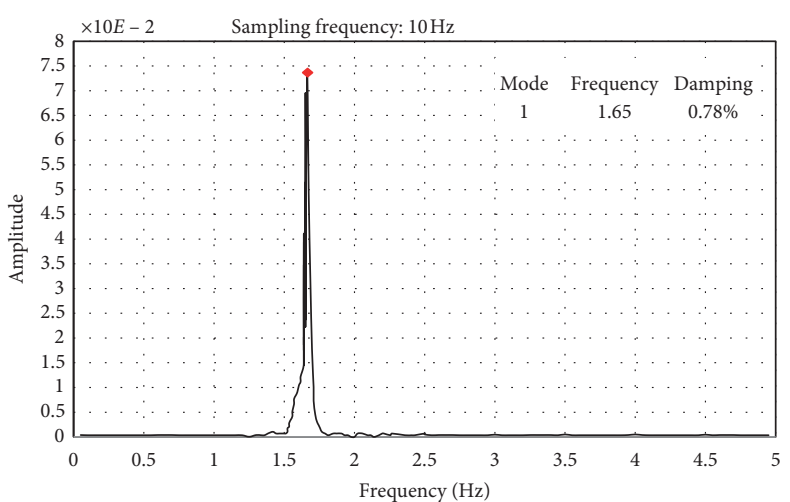

(b)

Figure 17: Monitoring results with the particle damper ( 9 alumina balls in container). (a) Acceleration-time history curve of the frame. (b) Identified frequency and damping ratio.

the glass balls. But the relationship of mass ratio and damping ratio is not linear. For example, the damping ratio of 14 glass balls is $0.68 \%$, but it drops to $0.63 \%$ when filled with 19 glass balls. The mass ratio increases while the damping ratio decreases. This is because when the fill ratio is relatively large, the movement space for the particles in the container is reduced. The kinetic energy of each ball reduces relatively. So the energy dissipation by the collision decreases. Even when the fill ratio is too large, the balls pile up and are difficult to move and the particle damper becomes invalid. In design, a balance between the high mass ratio and fill ratio is extremely important.

\section{Conclusions}

Particle dampers can increase the damping effect and effectively consume the vibration energy of the main structure. While metal particles have advantages in energy dissipation relatively, common building materials such as 


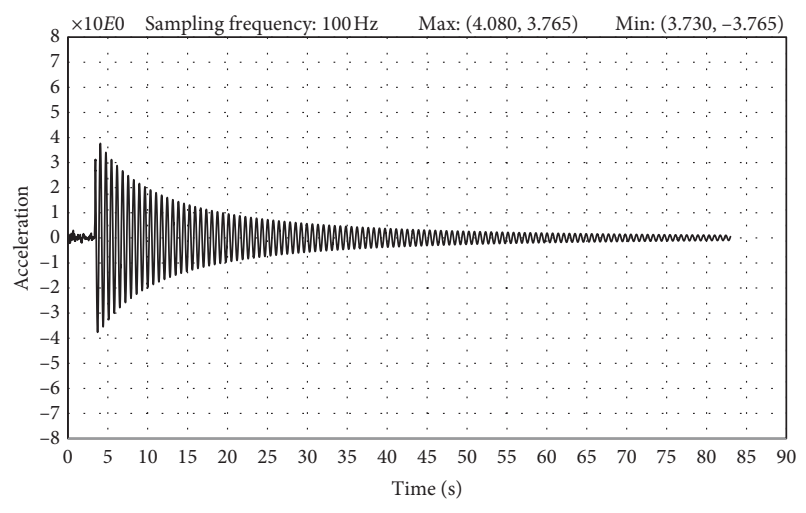

(a)

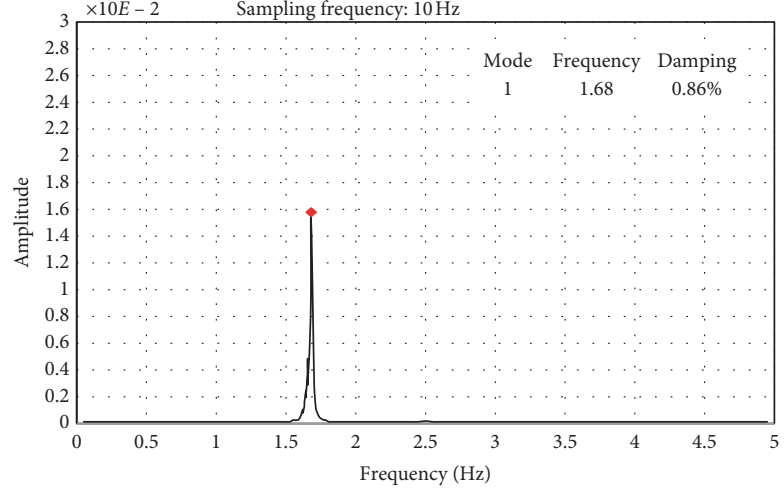

(b)

FIGURE 18: Monitoring results with the particle damper (9 steel balls in container). (a) Acceleration-time history curve of the frame. (b) Identified frequency and damping ratio.

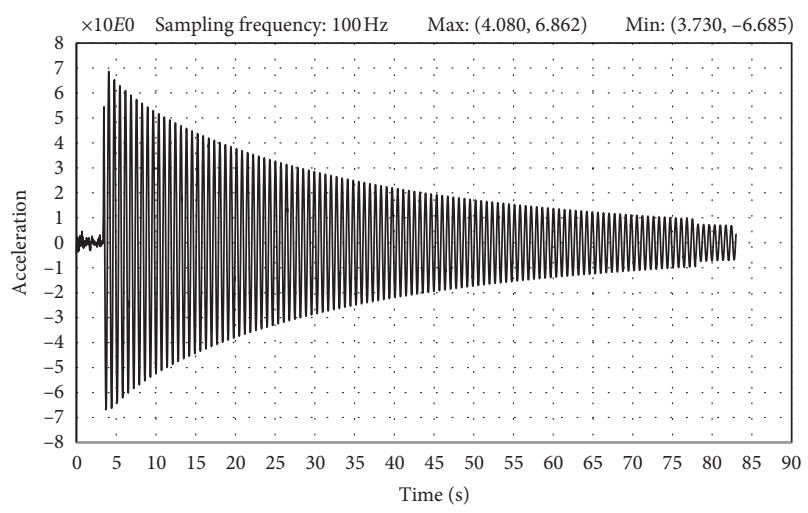

(a)

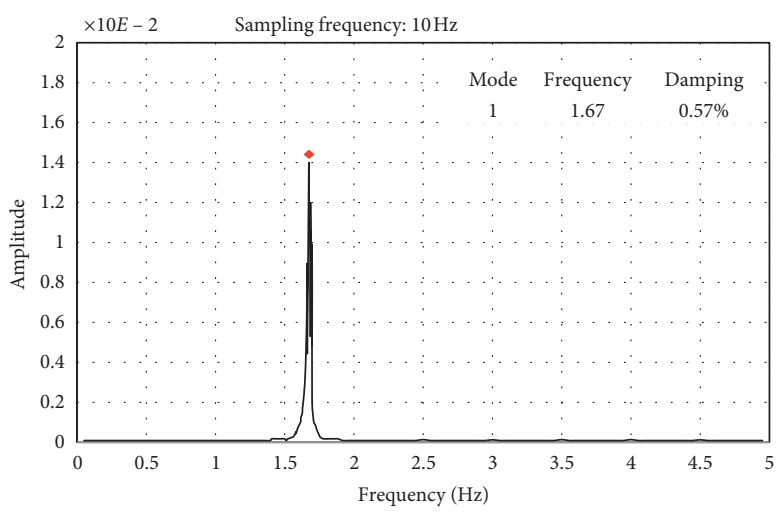

(b)

Figure 19: Monitoring results with the particle damper (14 glass balls in container). (a) Acceleration-time history curve of the frame. (b) Identified frequency and damping ratio.

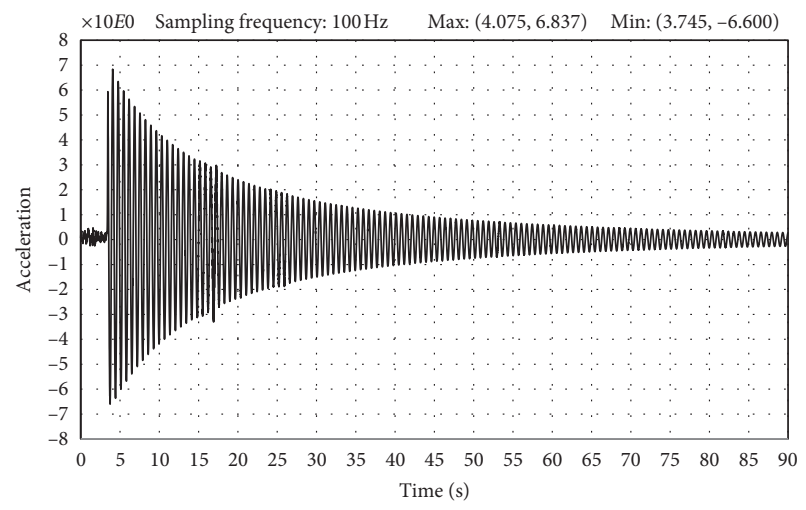

(a)

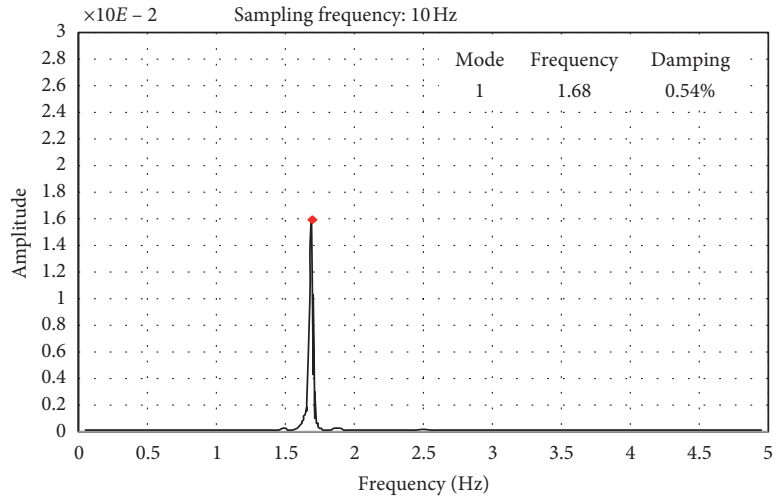

(b)

Figure 20: Monitoring results with the particle damper (19 glass balls in container). (a) Acceleration-time history curve of the frame. (b) Identified frequency and damping ratio.

stone and concrete can also be applied as particles in the damper, deduced form particle damping index $\zeta$. However, their practical effects on damping need to be verified by further theories and experiments. The mechanism of the particle damper is very complicated, because of various uncertainties and nonlinearities during the collision, as well as numerous mutual coupling factors which will affect the results. Effects of some factors can be derived from the theoretic model, while others require a lot of experimental researches. 


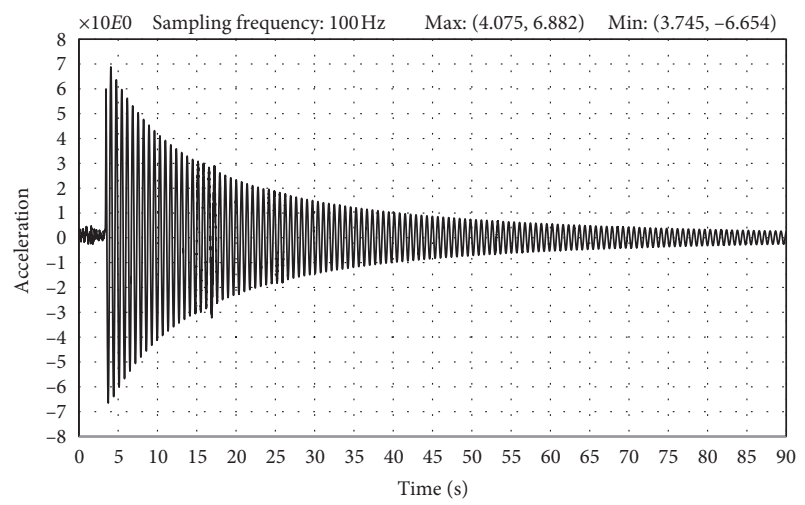

(a)

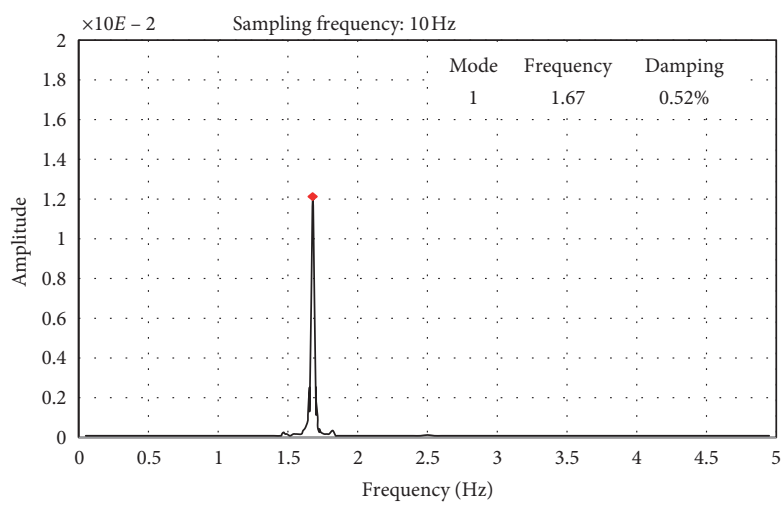

(b)

Figure 21: Monitoring results with the particle damper (7 alumina balls in container). (a) Acceleration-time history curve of the frame. (b) Identified frequency and damping ratio.

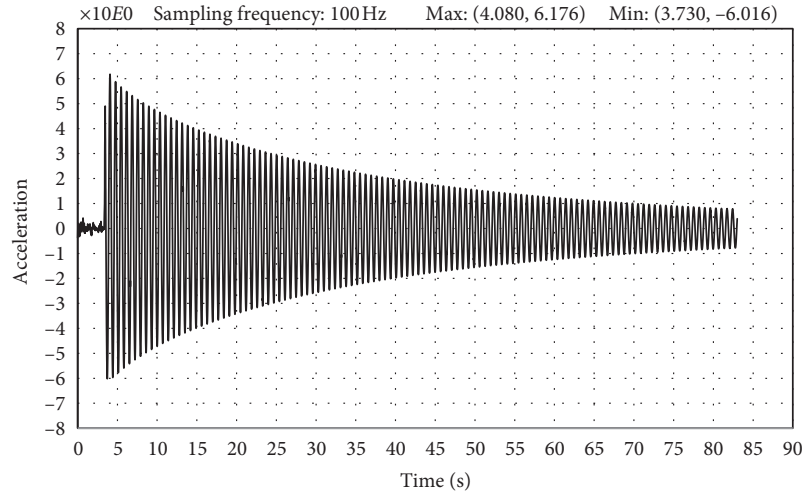

(a)

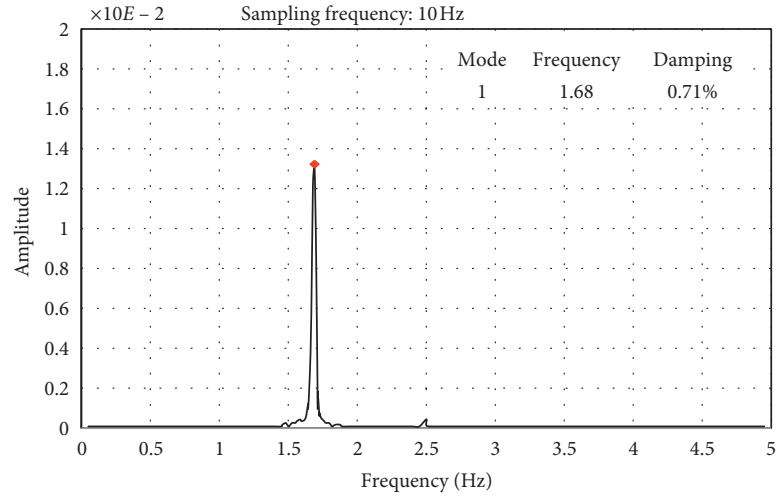

(b)

FIGURE 22: Monitoring results with the particle damper (3 steel balls in container). (a) Acceleration-time history curve of the frame. (b) Identified frequency and damping ratio.

This paper firstly gives a view of how to establish a theoretic model of the particle damper. The dynamic equation and energy dissipation coefficient of collision are revised from the Hertz contact theory, considering the friction of particles. Then, another collision model established by the finite element method verifies the reasonability of the theoretic model. The effects of different factors which will have an influence on the particle damping are discussed, and several conditional conclusions on optimized design are proposed. In spite of the aforementioned theoretical analysis, this paper also presents a particle damping index to evaluate the capability of energy dissipation of different particle materials, in order to facilitate the material selection. Finally, an experiment is developed to verify the character of the collision and energy dissipation. The feasibility of the proposed method to estimate the surface properties of different particles is proved by the free vibration experiment.

It is found that the properties of the particles have a significant impact on particle damping. The damping effect increases especially for materials with high elastic modulus and low yield strength, as well as some secondary factors, like high density, large normal velocity, and large dynamic friction coefficient.

\section{Data Availability}

The data used to support the findings of this study are available from the corresponding author upon request.

\section{Conflicts of Interest}

The authors declare no conflicts of interest.

\section{Authors' Contributions}

Xiaowei Li and Yue Yang carried out the numerical and finite element simulations. Xiaowei Li wrote the paper. Weixing Shi provided valuable discussions and revised the paper.

\section{Acknowledgments}

This study was supported by a project of the National Natural Science Foundation of China (Grant no. 51108346). 


\section{References}

[1] W. Shi, L. Wang, and Z. Lu, "Study on self-adjustable tuned mass damper with variable mass," Structural Control and Health Monitoring, vol. 25, no. 3, article e2114, 2018.

[2] W. Shi, L. Wang, Z. Lu, and H. Gao, "Study on adaptivepassive and semi-active eddy current tuned mass damper with variable damping," Sustainability, vol. 10, no. 2, p. 99, 2018.

[3] W. Shi, L. Wang, Z. Lu, and Q. Zhang, "Application of an artificial fish swarm algorithm in an optimum tuned mass damper design for a pedestrian bridge," Applied Sciences, vol. 8, no. 2, p. 175, 2018.

[4] W. Shi, L. Wang, Z. Lu, and H. Wang, "Experimental and numerical study on adaptive-passive variable mass tuned mass damper," Journal of Sound and Vibration, vol. 452, pp. 97-111, 2019.

[5] B. F. Spencer Jr., and S. Nagarajaiah, "State of the art of structural control," Journal of Structural Engineering, vol. 129, no. 7, pp. 845-856, 2003.

[6] S. Nagarajaiah, "Adaptive passive, semiactive, smart tuned mass dampers: identification and control using empirical mode decomposition, hilbert transform, and short-term fourier transform," Structural Control and Health Monitoring, vol. 16, no. 7-8, pp. 800-841, 2009.

[7] L. Wang, W. Shi, and Y. Zhou, "Study on self-adjustable variable pendulum tuned mass damper," The Structural Design of Tall and Special Buildings, vol. 28, no. 1, article e1561, 2019.

[8] L. Wang, W. Shi, X. Li, Q. Zhang, and Y. Zhou, "An adaptivepassive retuning device for a pendulum tuned mass damper considering mass uncertainty and optimum frequency," Structural Control and Health Monitoring, vol. 26, no. 7, article e2377, 2019.

[9] R. D. Nayeri, S. F. Masri, and J. P. Caffrey, "Studies of the performance of multi-unit impact dampers under stochastic excitation," Journal of Vibration and Acoustics, vol. 129, no. 2, pp. 239-251, 2007.

[10] S. F. Masri, "Analytical and experimental studies of multipleunit impact dampers," Journal of the Acoustical Society of America, vol. 45, no. 5, pp. 1111-1117, 1969.

[11] W. Liu, G. R. Tomlinson, and J. A. Rongong, "The dynamic characterisation of disk geometry particle dampers," Journal of Sound and Vibration, vol. 280, no. 3-5, pp. 849-861, 2005.

[12] C. X. Wong, M. C. Daniel, and J. A. Rongong, "Energy dissipation prediction of particle dampers," Journal of Sound and Vibration, vol. 319, no. 1-2, pp. 91-118, 2009.

[13] M. Saeki, "Analytical study of multi-particle damping," Journal of Sound and Vibration, vol. 281, no. 3-5, pp. 11331144, 2005.

[14] J. Chen and C. T. Georgakis, "Tuned rolling-ball dampers for vibration control in wind turbines," Journal of Sound and Vibration, vol. 332, no. 21, pp. 5271-5282, 2013.

[15] P. Zhang, G. Song, H.-N. Li, and Y.-X. Lin, "Seismic control of power transmission tower using pounding TMD," Journal of Engineering Mechanics, vol. 139, no. 10, pp. 1395-1406, 2013.

[16] M. Sánchez and C. Manuel Carlevaro, "Nonlinear dynamic analysis of an optimal particle damper," Journal of Sound and Vibration, vol. 332, no. 8, pp. 2070-2080, 2013.

[17] Y. M. Parulekar and G. R. Reddy, "Passive response control systems for seismic response reduction: a state-of-the-art review," International Journal of Structural Stability and Dynamics, vol. 9, no. 1, pp. 151-177, 2009.

[18] B. M. Shah, J. J. Nudell, K. R. Kao, L. M. Keer, Q. Jane Wang, and K. Zhou, "Semi-active particle-based damping systems controlled by magnetic fields," Journal of Sound and Vibration, vol. 330, no. 2, pp. 182-193, 2011.

[19] B. Fu, H. Jiang, and T. Wu, "Experimental study of seismic response reduction effects of particle damper using substructure shake table testing method," Structural Control and Health Monitoring, vol. 26, no. 2, article e2295, 2019.

[20] M. Gharib and S. Ghani, "Free vibration analysis of linear particle chain impact damper," Journal of Sound and Vibration, vol. 332, no. 24, pp. 6254-6264, 2013.

[21] Z.-L. Zhang, J.-B. Chen, and J. Li, "Theoretical study and experimental verification of vibration control of offshore wind turbines by a ball vibration absorber," Structure and Infrastructure Engineering, vol. 10, no. 8, pp. 1087-1100, 2014.

[22] K. Li and A. P. Darby, "A buffered impact damper for multidegree-of-freedom structural control," Earthquake Engineering \& Structural Dynamics, vol. 37, no. 13, pp. 1491-1510, 2008.

[23] B. Darabi and J. A. Rongong, "Polymeric particle dampers under steady-state vertical vibrations," Journal of Sound and Vibration, vol. 331, no. 14, pp. 3304-3316, 2012.

[24] G. Michon, A. Almajid, and G. Aridon, "Soft hollow particle damping identification in honeycomb structures," Journal of Sound and Vibration, vol. 332, no. 3, pp. 536-544, 2013.

[25] B. Yao, Q. Chen, H. Y. Xiang, and X. Gao, "Experimental and theoretical investigation on dynamic properties of tuned particle damper," International Journal of Mechanical Sciences, vol. 80, pp. 122-130, 2014.

[26] W. Yan, W. Xu, J. Wang, and Y. Chen, "Experimental research on the effects of a tuned particle damper on a viaduct system under seismic loads," Journal of Bridge Engineering, vol. 19, no. 3, pp. 165-184, 2014.

[27] M. Ben Romdhane, N. Bouhaddi, M. Trigui, E. Foltête, and M. Haddar, "The loss factor experimental characterisation of the non-obstructive particles damping approach," Mechanical Systems and Signal Processing, vol. 38, no. 2, pp. 585-600, 2013.

[28] A. Papalou and S. F. Masri, "Response of impact dampers with granular materials under random excitation," Earthquake Engineering \& Structural Dynamics, vol. 25, no. 3, pp. 253267, 1996.

[29] T. A. Jadhav and P. J. Awasare, "Enhancement of particle damping effectiveness using multiple cell enclosure," Journal of Vibration and Control, vol. 22, no. 6, pp. 1516-1525, 2016.

[30] Y. Wang, B. Liu, A. Tian, and W. Tang, "Experimental and numerical investigations on the performance of particle dampers attached to a primary structure undergoing free vibration in the horizontal and vertical directions," Journal of Sound and Vibration, vol. 371, pp. 35-55, 2016.

[31] C. Cempel and G. Lotz, "Efficiency of vibrational energy dissipation by moving shot," Journal of Structural Engineering, vol. 119, no. 9, pp. 2642-2652, 1993.

[32] E. M. Kerwin Jr., Macromechanisms of Damping in Composite Structure. Internal Friction, Damping, and Cyclic Plasticity, ASTM International, West Conshohocken, PA, USA, 1965.

[33] Z. Xu, M. Y. Wang, and T. Chen, "Particle damping for passive vibration suppression: numerical modelling and experimental investigation," Journal of Sound and Vibration, vol. 279, no. 3-5, pp. 1097-1120, 2005.

[34] Z. Lu, B. Huang, and Y. Zhou, "Theoretical study and experimental validation on the energy dissipation mechanism of particle dampers," Structural Control and Health Monitoring, vol. 25, no. 4, article e2125, 2018. 
[35] Z. Lu, Z. Wang, S. F. Masri, and X. Lu, "Particle impact dampers: past, present, and future," Structural Control and Health Monitoring, vol. 25, no. 1, article e2058, 2018.

[36] Z. Lu, X. Chen, and Y. Zhou, "An equivalent method for optimization of particle tuned mass damper based on experimental parametric study," Journal of Sound and Vibration, vol. 419, pp. 571-584, 2018.

[37] Z.-w. Xu, B.-q. Tao, and X.-q. Huang, "Theoretical and experimental research on vibration absorption mechanisms of NOPD particles," Acta Aeronautica Et Astronautica Sinica, vol. 22, no. 4, pp. 347-350, 2001.

[38] R. Temam, Mathematical Problems in Plasticity, Courier Dover Publications, Mineola, NY, USA, 2018.

[39] J. Zhang, "The loss of kinetic energy in the collision of twobody with sliding friction," Mechanics in Engineering, vol. 32, no. 5, pp. 89-91, 2010. 


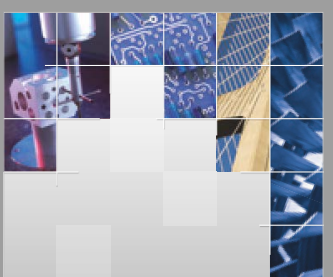

\section{Enfincering}
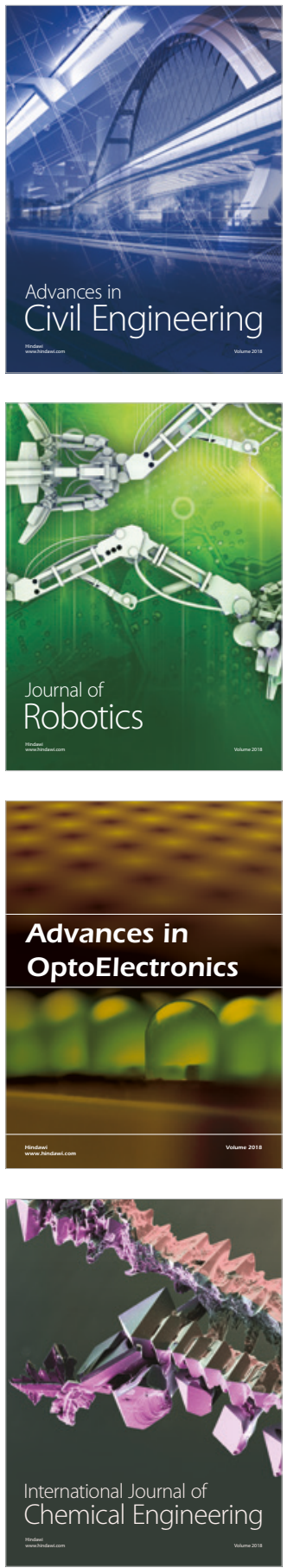

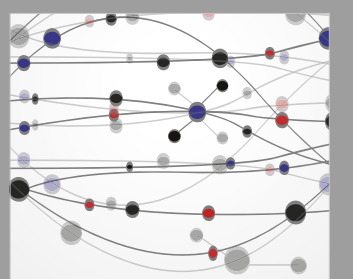

\section{Rotating \\ Machinery}

The Scientific World Journal

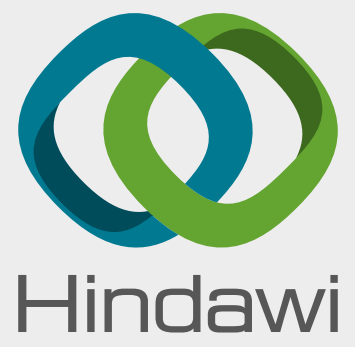

Submit your manuscripts at

www.hindawi.com
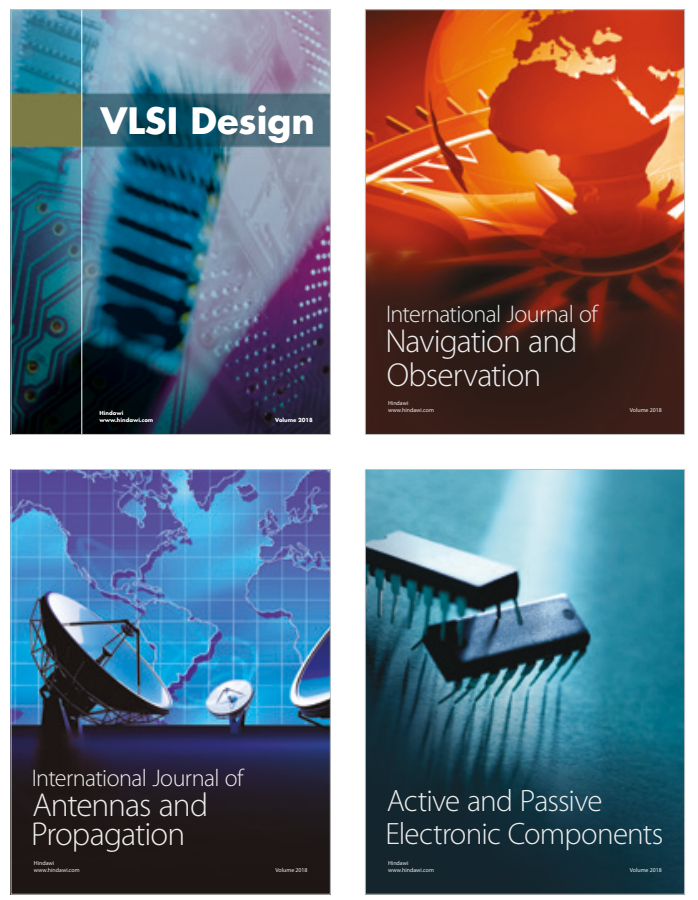
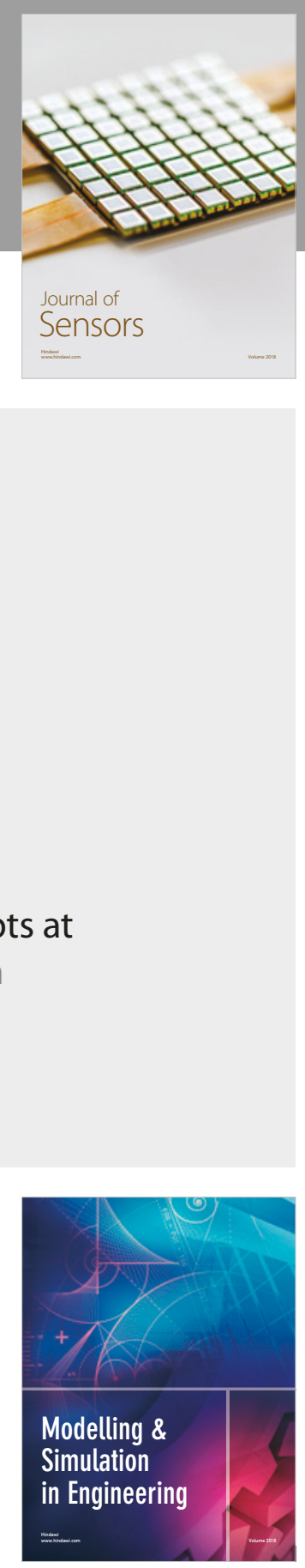

\section{Advances \\ Multimedia}
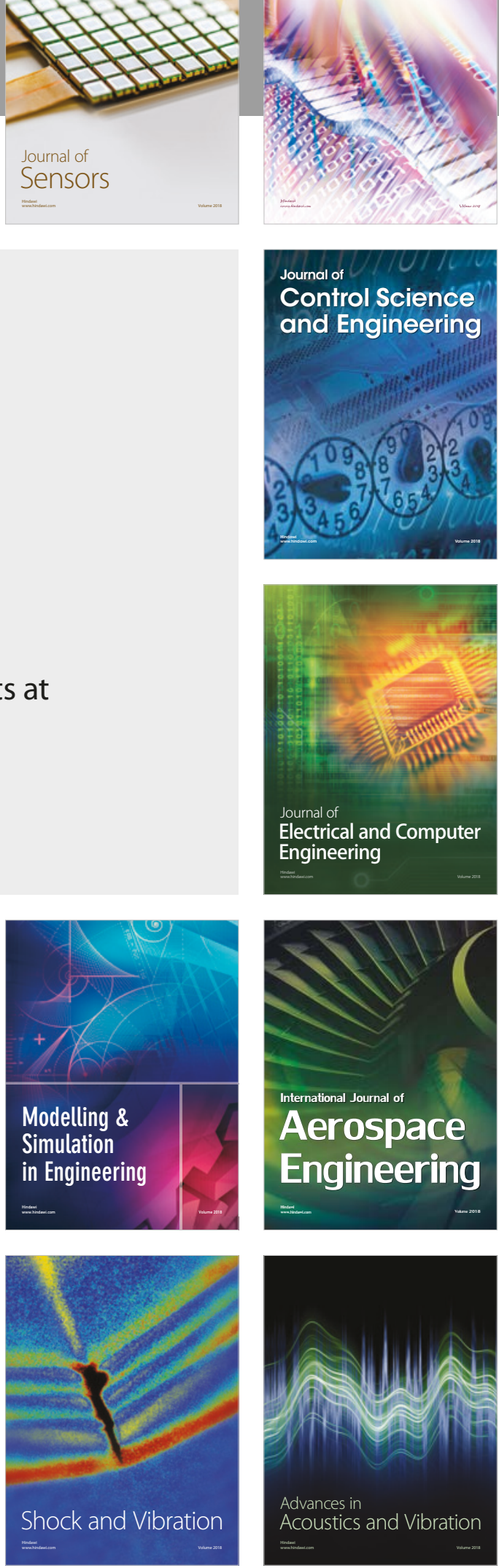